\title{
Parental nutritional programming and a reminder during juvenile stage affect growth, lipid metabolism and utilisation in later developmental stages of a marine teleost, the gilthead sea bream (Sparus aurata)
}

\author{
Serhat Turkmen*, Maria J. Zamorano, Hipólito Fernández-Palacios, Carmen M. Hernández-Cruz, \\ Daniel Montero, Lidia Robaina and Marisol Izquierdo \\ Aquaculture Research Group (GIA), Research Institute in Sustainable Aquaculture and Marine Conservation (IU-ECOAQUA), \\ Universidad de Las Palmas de Gran Canaria, Crta. Taliarte s/n, 35214 Telde, Spain
}

(Submitted 1 May 2017 - Final revision received 9 August 2017 - Accepted 11 August 2017)

\section{Abstract}

Nutrition during periconception and early development can modulate metabolic routes to prepare the offspring for adverse conditions through a process known as nutritional programming. In gilthead sea bream, replacement of fish oil (FO) with linseed oil (LO) in broodstock diets improves growth in the 4-month-old offspring challenged with low-FO and low-fishmeal (FM) diets for 1 month. The present study further investigated the effects of broodstock feeding on the same offspring when they were 16 months old and were challenged for a second time with the low-FM and low-FO diet for 2 months. The results showed that replacement of parental moderate-FO feeding with LO, combined with juvenile feeding at 4 months old with low-FM and low-FO diets, significantly $(P<0 \cdot 05)$ improved offspring growth and feed utilisation of low-FM/FO diets even when they were 16 months old: that is, when they were on the verge of their first reproductive season. Liver fatty acid composition was significantly affected by broodstock or reminder diets as well as by their interaction. Moreover, the reduction of long-chain PUFA and increase in $\alpha$-linolenic acid and linoleic acid in broodstock diets lead to a significant down-regulation of hepatic lipoprotein lipase $(P<0 \cdot 001)$ and elongation of very long-chain fatty acids protein $6(P<0 \cdot 01)$. Besides, fatty acid desaturase 2 values were positively correlated to hepatic levels of $18: 4 n-3,18: 3 n-6,20: 5 n-3,22: 6 n-3$ and $22: 5 n-6$. Thus, this study demonstrated the long-term nutritional programming of gilthead sea bream through broodstock feeding, the effect of feeding a 'reminder' diet during juvenile stages to improve utilisation of low-FM/FO diets and fish growth as well as the regulation of gene expression along the fish's life-cycle.

Key words: Nutritional adaptation of offspring: Long-term effects of parental nutrition: Hepatic gene expression: Fatty acid desaturase: Epigenetics in aquaculture

Aquaculture is the fastest-growing animal production sector accounting, at present, for more than $50 \%$ of worldwide fish consumption $^{(1)}$, but one major issue concerning such development is the over-dependence of fish feeds on capture fisheryderived raw materials such as fishmeal (FM) and fish oil (FO) ${ }^{(2)}$. The established beneficial roles of FO on human health ${ }^{(3)}$ and the use of FO, albeit in small proportions, in other animal production systems, have led to an increase in the demand for this raw material, consequently, raising the prices. Despite great achievements in the reduction of FM in diets of marine fish species $^{(4-8)}$, complete replacement of FO still remains a major challenge. Moreover, complete substitution of FO negatively affects the immune system and stress and disease resistance ${ }^{(9)}$ as well as reduces the fillet content of long-chain $n-3$ PUFA ( $n$-3 LC-PUFA, includes twenty or more carbon atoms), such as
EPA and DHA, negatively affecting the nutritional value of fish flesh for humans ${ }^{(10-13)}$

FO is rich in $n$-3 LC-PUFA, whereas vegetable oil (VO) sources, except in some cases ${ }^{(14)}$, lack the essential fatty acids (EFA) for marine fish such as EPA and DHA but can have significant amounts of $\alpha$-linolenic acid (ALA), 18:3n-3, and linoleic acid (LA), 18:2n-6, which are biological precursors of EFA. Yet, the bioconversion of 18-carbon PUFA to EPA and DHA depends on the elongation and desaturation capacity of the fish species $^{(15,16)}$. Generally speaking, whereas freshwater fish possess the ability to convert ALA and LA into LC-PUFA ${ }^{(17,18)}$, marine fish do not possess the sufficient enzyme activity ${ }^{(19)}$. Nonetheless, LC-PUFA synthesis capacity also appears to differ among marine species $^{(20-23)}$. The higher LC-PUFA biosynthesis capacity in freshwater fish in comparison with that of marine fish could be

Abbreviations: ALA, $\alpha$-linolenic acid; f, fish oil-based diet; elovl6, elongation of very long-chain fatty acids protein 6; fads2, fatty acid desaturase 2; FM, fishmeal; FO, fish oil; HL, $20 \%$ fish oil-80\% linseed oil; LA, linoleic acid; LL, $40 \%$ fish oil-60\% linseed oil; LO, linseed oil; lpl, lipoprotein lipase; v, reminder diet; VO, vegetable oil.

* Corresponding author: S. Turkmen, email serhatturkmen@gmail.com 
related to differences in the feeding habits and nutrient intake, with marine fish having a continuous access to LC-PUFA-rich sources throughout their lives ${ }^{(24,25)}$. Besides, these differences among fish species have been related to the diverse evolution of certain genes involved in lipid biosynthesis ${ }^{(16)}$

Recent evidence suggests that environmental factors experienced by the parents can have long-lasting effects in the offspring or in the later generations ${ }^{(26,27)}$. Thus, early environmental signs, such as available nutrients during reproduction, can modulate metabolic routes and offspring phenotype ${ }^{(27-29)}$. This type of metabolic regulation, known as 'nutritional programming', has been principally derived from mammalian models, because of their potential effects on development of metabolic disorders in humans in later life ${ }^{(30)}$. Therefore, better understanding of the outcomes of parental nutrition and the underlying mechanisms can contribute to the prevention of consequences in the offspring. Besides, nutritional programming may also have potential applications in animal production $^{(31)}$. In aquaculture, one of the potential beneficial applications of nutritional programming may be the production of individuals better prepared to use some feedstuffs supplying or lacking in specific nutrients, such as VO and plant-protein sources. For instance, specific fat and dietary fatty acid supply during embryonic and offspring development may adjust fish metabolism for better utilisation of 18-carbon fatty acids later in life. Thus, parental nutritional interventions can modulate epigenetic mechanisms that control 'metabolic decisions' that are meiostatically and mitotically stable through life in humans ${ }^{(32)}$, rodents $^{(33,34)}$ and cattle ${ }^{(35)}$. In fish, nutritional programming studies have mostly focused on early feeding ${ }^{(36-43)}$, whereas parental nutritional interventions are scarcer $^{(44-46)}$

The gilthead sea bream (Sparus aurata), is a multi-batch spawner whose oligolecitic eggs largely depend on their continuous intake of nutrients during reproduction ${ }^{(47)}$. For this reason, egg nutrient content of the gilthead sea bream can be markedly affected by the parental diet even during the spawning season, in turn, affecting early embryonic development ${ }^{(48)}$. Our previous studies have demonstrated that feeding gilthead sea bream broodstock with high-linseed oil (LO) diets markedly affects fecundity, spawn quality and growth of 45-dafter-hatch larvae and 4-month-old juveniles ${ }^{(45)}$. Interestingly, when 4-month-old juveniles were challenged with a low-FM and low-FO diet, offspring from parents fed a replacement of $60 \%$-FO with LO showed a faster growth and better feed utilisation than those whose parents had been fed with $\mathrm{FO}^{(45)}$. However, the potential persistence of the effects of broodstock nutritional history on the offspring later in life is still unknown.

Further, little is known on the physiological or molecular mechanisms involved in the effect of parental diets on the metabolic performance of the offspring. When $n$-3 LC-PUFA are limited and the 18-C atom fatty acids are available in gilthead sea bream diet, the gene for fatty acid desaturase 2 (fads2), the key-limiting enzyme for LC-PUFA synthesis, is up-regulated ${ }^{(49)}$. Long-chain fatty acid synthesis also involves chain-elongation catalysed by elongases (Elovl) with different substrate preferences ${ }^{(50)}$. Among them, Elovl6 is a key lipogenic enzyme that elongates long-chain SFA and MUFA of 12, 14 and 16 carbon atoms, which has received much attention because of its importance in metabolic disorders ${ }^{(51)}$. Besides, LC-PUFA may have a direct effect on the expression of other genes related to lipid or carbohydrate metabolism ${ }^{(52)}$. Lipoprotein lipase $(l p l)$ facilitates the tissue uptake of circulating fatty acids ${ }^{(53)}$ from lipoproteins and its expression in the liver can be regulated by $n-3$ LC-PUFA $^{(54)}$. The provision of energy is accomplished by $\beta$-oxidation of free fatty acids transported into the mitochondria in the form of fatty acyl-carnitine esters by carnitine acyltransferases, such as carnitine palmitoyltransferases ${ }^{(15)}$. Replacement of FO with VO changes the fatty acid composition of liver and muscle, affecting the $\beta$-oxidation capacity and regulating the expression of $c$ tI and $c$ tII genes ${ }^{(17,55-57)}$. $\beta$-Oxidation also takes place in the peroxisome and is modulated by PPAR. A total of three different PPAR isoforms $(\alpha, \beta, \gamma)$ have been characterised in gilthead sea bream, ppar $\alpha$ being the major form expressed in the liver ${ }^{(58)}$. PPAR are nuclear receptors that regulate differentiation, growth and metabolism and, in mammals, epigenetic mechanisms have been described to regulate these processes involving all the PPAR isoforms ${ }^{(59)}$. For instance, feeding pregnant rats a protein-restricted diet reduces methylation of the ppara promoter in the offspring and the hypomethylation persists into adulthood ${ }^{(60)}$. Finally, another gene potentially regulated by LC-PUFA is cyclo-oxygenase- 2 (cox2), a key enzyme in prostanoid biosynthesis ${ }^{(61)}$

The objective of the present study was to explore the potential persistence of nutritional programming through parental feeding in offspring later in life and to analyse the physiological or molecular mechanisms implied. For this purpose, the offspring of gilthead sea bream broodstock fed diets with different FO/LO levels were followed up for 18 months until the beginning of first gonad development and nutritionally challenged at 4 and 16 months with low FM and FO diets. The effects of both broodstock feeding and nutritional challenge on growth, chemical and fatty acid composition of muscle and liver as well as on the expression of selected genes in the liver were investigated.

\section{Methods}

\section{Experimental animals}

All fish were obtained from spontaneous spawns of gilthead sea bream broodstock fed three diets with three levels of FO substitution with LO: $100 \%$ FO, 40\% FO-60\% LO (LL) and $20 \%$ FO-80\% LO $(\mathrm{HL})^{(45)}$. Offspring from all groups were fed the same commercial diet during larval rearing, weaning and during the growing period until they reached 4 months of age $(120 \mathrm{~d})^{(45)}$. At this stage, triplicate groups of juveniles were nutritionally challenged for 1 month with either a high-FM/FO diet (f) or with a high-VM/LO diet (v) named as 'reminder diet' in the present study. Details of the broodstock feeding, juvenile nutritional challenge (reminder) at 4 months and feed formulation have been reported earlier ${ }^{(45)}$. After this first nutritional challenge (reminder), fish were maintained separately in 1000 litre tanks and fed the same commercial diet until they were 16 months old for use in the present study. A schematic view of this nutritional programming history is shown in Fig. 1. 


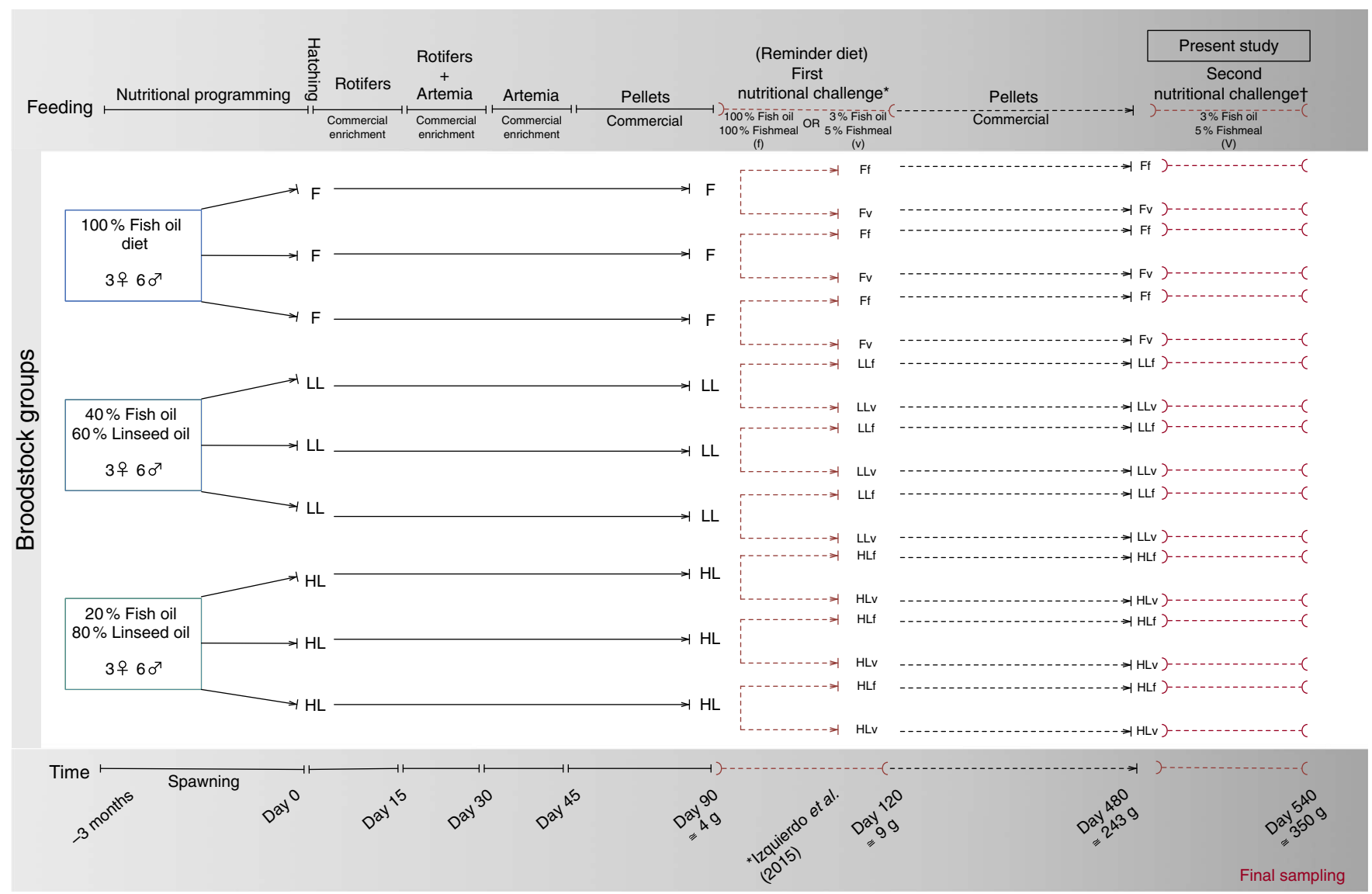

Fig. 1. Schematic view of the nutritional programming history of gilthead sea bream. F, $100 \%$ fish oil; LL, $40 \%$ fish oil- $60 \%$ linseed oil; and $\mathrm{HL}$, $20 \%$ fish oil- $80 \%$ linseed oil; f, fish oil-based diet; v, reminder diet. * Previous publication, Izquierdo et al. $(2015)^{(45)}$. † Time of the present study.

In the present study, 16-month-old offspring sea breams of homogeneous weight were selected and distributed into 18500litre light-grey fibreglass cylinder tanks $\left(2 \cdot 8 \mathrm{~kg} / \mathrm{m}^{3}\right)$. Each tank contained thirty fish with mean initial body weight of 243.2 (sD12.7) g. Tanks were supplied with filtered seawater (37 parts per million (ppm) salinity), which entered from the tank surface and drained from the bottom at a rate of 250 litre/ $h$ to maintain a high water quality, which was tested daily and no deterioration was observed. $\mathrm{O}_{2}$ level, water temperature and $\mathrm{pH}$ were monitored in real-time using Miranda aquaculture water quality monitoring system (Innovaqua). Water was continuously aerated $(125 \mathrm{ml} / \mathrm{min})$, attaining an average of 6.8 (SD 0.8$) \mathrm{ppm}$ dissolved $\mathrm{O}_{2}$ during the experimental period. The average water temperature and $\mathrm{pH}$ for the duration of the trial were $24 \cdot 6 \pm 0 \cdot 6^{\circ} \mathrm{C}$ and $7 \cdot 89$, respectively. Natural photoperiod was maintained during the whole experimental period (10- $\mathrm{h}$ light).

\section{Experimental diet}

The experimental diet was formulated and produced by Biomar to be low in FO (3\%) and FM (5\%). Thus, the diet was high in oleic acid $(18: 1 n-9)$, LA $(18: 2 n-6)$ and ALA $(18: 3 n-3)$ (Table 1). Juveniles from each group were fed daily until apparent satiation for $60 \mathrm{~d}$, three times a day at 09.00, 13.00 and 17.00 hours. The feed was supplied in small portions
$(<5-6$ pellets at a time) to ensure that all feed was eaten. After each feeding, uneaten feed was collected, kept in aluminium oven trays, dried overnight at $105^{\circ} \mathrm{C}$ and weighted to calculate feed intake.

\section{Biochemical analyses}

Moisture, protein ${ }^{(63)}$ and crude lipid ${ }^{(64)}$ contents of the tissue samples and diets were analysed. Fatty acid methyl esters were obtained by trans-methylation of crude lipids as previously described ${ }^{(65)}$. Fatty acid methyl esters were separated using GLC (GC-14A; Shimadzu) following the conditions described previously ${ }^{(6)}$ and identified by comparison with previously characterised standards and GLC-MS (Polaris QTRACE ${ }^{\mathrm{TM}}$ Ultra; Thermo Fisher Scientific).

\section{Molecular studies}

Liver samples from three fish per each tank (nine per group) were collected at the beginning (480-d-old fish) and at the end of the feeding challenge (540-d-old fish). Samples were collected on ice from fish kept unfed for $24 \mathrm{~h}$, each tissue sample from one individual was assigned to a corresponding 1.5-ml Eppendorf tube and was snap frozen in liquid $\mathrm{N}_{2}$ immediately after sampling. The samples were then stored at $80^{\circ} \mathrm{C}$ until RNA extraction and analyses. RNA was extracted 
Table 1. Main ingredients*, energy, protein and $\%$ total fatty acids contents of diet for the nutritional challenge of gilthead sea bream juveniles obtained from broodstock fed diets $100 \%$ fish oil (FO), $40 \%$ FO-60\% linseed oil (LO) and 20\% FO-80\% LO during spawning

\begin{tabular}{|c|c|c|c|}
\hline Main ingredients (\%) & $\%$ & $\begin{array}{l}\text { Proximate } \\
\text { composition }\end{array}$ & $(\% \mathrm{DM})$ \\
\hline Fishmeal SA† 68 super prime & 5.00 & Crude lipids & 21.7 \\
\hline $\begin{array}{l}\text { Fishmeal alternative protein } \\
\text { sources } \ddagger\end{array}$ & $54 \cdot 50$ & Crude protein & $45 \cdot 1$ \\
\hline Rapeseed meal cake & $11 \cdot 30$ & Moisture & $9 \cdot 0$ \\
\hline Wheat & 6.89 & Ash & $5 \cdot 4$ \\
\hline Fish oil SA† & 3.00 & & \\
\hline Vegetable oil mix§ & $13 \cdot 00$ & $\begin{array}{l}\text { Gross energy } \\
(\mathrm{MJ} / \mathrm{kg} \text {, as is) }\end{array}$ & $22 \cdot 5$ \\
\hline$\%$ Total fatty acids & & $\%$ Total fatty acids & \\
\hline $14: 0$ & $6 \cdot 6$ & $18: 3 n-3$ & 11.8 \\
\hline $14: 1 n-5$ & $0 \cdot 1$ & $18: 4 n-3$ & 0.4 \\
\hline $15: 0$ & $0 \cdot 1$ & $18: 4 n-1$ & 0.0 \\
\hline 16 : 0iso & 0.0 & $20: 0$ & 0.4 \\
\hline $16: 0$ & $12 \cdot 3$ & $20: 1 n-9$ & 0.0 \\
\hline $16: 1 n-7$ & $2 \cdot 1$ & $20: 1 n-7$ & 1.0 \\
\hline $16: 1 n-5$ & 0.1 & $20: 1 n-5$ & 0.1 \\
\hline $16: 2 n-4$ & 0.2 & $20: 2 n-9$ & 0.0 \\
\hline $17: 0$ & 0.3 & $20: 2 n-6$ & 0.1 \\
\hline $16: 3 n-4$ & $0 \cdot 1$ & $20: 3 n-9$ & 0.0 \\
\hline $16: 3 n-3$ & 0.0 & $20: 3 n-6$ & 0.0 \\
\hline $16: 3 n-1$ & 0.0 & $20: 4 n-6$ & 0.2 \\
\hline $16: 4 n-3$ & 0.4 & $20: 3 n-3$ & 0.0 \\
\hline $18: 0$ & $3 \cdot 2$ & $20: 4 n-3$ & 0.1 \\
\hline $18: 1 n-9$ & $32 \cdot 3$ & $20: 5 n-3$ & 2.5 \\
\hline $18: 1 n-7$ & $2 \cdot 3$ & $22: 1 n-11$ & 0.1 \\
\hline $18: 1 n-5$ & 0.0 & $22: 1 n-9$ & 0.3 \\
\hline $18: 2 n-9$ & 0.0 & $22: 4 n-6$ & 0.0 \\
\hline $18: 2 n-6$ & $20 \cdot 3$ & $22: 5 n-6$ & 0.1 \\
\hline $18: 2 n-4$ & 0.1 & $22: 5 n-3$ & 0.3 \\
\hline $18: 3 n-6$ & 0.1 & $22: 6 n-3$ & 1.7 \\
\hline $18: 3 n-4$ & 0.0 & & \\
\hline
\end{tabular}

* Please see Torrecillas et al. ${ }^{(62)}$ for the complete list of feed ingredients.

† South American, Superprime (Feed Service).

‡ Blood meal spray (Daka), soya protein concentrates $60 \%$ (Svane Shipping), maize gluten 60 (Cargill), wheat gluten (Cargill).

$\S$ Linseed (2.6\%) (Ch. Daudruy), rapeseed (5.2\%) (Emmelev) and palm oils $(5.2 \%)$ (Cargill).

using Qiagen RNeasy Mini Kit (Qiagen). Before real-time PCR analysis two different potential housekeeping genes, $\beta$-actin $(\beta$-act) and ribosomal protein L27 ( $r p l 27)$, were tested. Data from duplicate samples ( $n$ 18) using the two candidate housekeeping genes were compared using an online program (http://leonxie.esy.es/RefFinder/?type=reference) $\left(\right.$ RefFinder ${ }^{(67)}$ and $\beta$-act was selected as the most suitable housekeeping gene for the present study $\left(\beta\right.$-act, threshold cycle $\left(C_{t}\right)$ values: $\min =$ 18.9, $\max =20 \cdot 6$, mean $=19 \cdot 64, \mathrm{SD}=0 \cdot 5 ; \mathrm{ppl} 27: \min =17 \cdot 0 \mathrm{max}=$ $21 \cdot 2$, mean $=19 \cdot 1, \mathrm{SD}=1 \cdot 01)$.

Real-time quantitative PCR were performed in an iQ5 Multicolor Real-Time PCR detection system (Bio-Rad) using $\beta$-act as the housekeeping gene in a final volume of $15 \mu \mathrm{l} /$ reaction well and with $100 \mathrm{ng}$ of total RNA reverse-transcribed to complementary DNA (cDNA). Samples, housekeeping gene, cDNA template and reaction blanks were analysed in duplicates (Table 2). Primer efficiency was tested with serial dilutions of a cDNA pool (1:5, 1:10, 1:100 and 1:1000). A single ninetysix-well PCR plate was used to analyse each gene, primer efficiency and blank samples (Multiplate; Bio-Rad). Melting-curve analysis was performed and amplification of a single product was confirmed after each run. Fold expression of each gene was determined by delta-delta $C_{T}$ method $\left(2^{-\Delta \Delta C_{T}}\right)^{(66)}$. PCR efficiencies were similar and no efficiency correction was required $^{(71,72)}$ (Table 2). Fold expression was related to that of offspring obtained from FO diet-fed broodstock and fed commercial diets throughout their life (Ff group).

\section{Statistical analysis}

Data on growth and biochemical composition were statistically analysed using two-way ANOVA, using broodstock diet and reminder diet as fixed factors in IBM SPSS version 23.0.0.2 for Mac (IBM SPSS Inc.). Data were split into groups based on each fixed factor (broodstock and reminder diet) and compared with one-way ANOVA. Scheffe's post hoc multiple comparisons for broodstock and reminder diet, separately, assessed differences between groups. Before the analysis of data, equality of variances was tested using Levene's test and distribution of data using Shapiro-Wilk tests. All data except cox 2 gene expression showed normal distribution and equality of variances.

Gene expression data (except for cox2) were analysed by means of two-way ANOVA using broodstock and reminder diet as fixed factors. Expression data were next analysed using Welch's ANOVA and subsequently compared with the GamesHowell test for identification of differences between groups. The fixed factor for Welch's ANOVA was experimental groups in gene expression data analysis. Pearson's correlation test was performed using $\mathrm{R}$ ( $\mathrm{R}$ Foundation for Statistical Computing). Gene expression figures were created using lattice package (version $0.20-33)^{(73)}$ downloaded from the comprehensive $\mathrm{R}$ Archive Network library. The sample size for all analysed data was nine and data were expressed as means and standard deviations.

\section{Results}

\section{Growth performance}

The low-FM/FO diet was well accepted and there were no significant differences in feed intake among fish groups (mean, 3.95 (sD 0.39) kg, $P>0.05$ ). At the beginning of the trial, there were no significant differences in fish body weight (mean, 243.2 $(\mathrm{sD} 12 \cdot 7) \mathrm{g}$ ) among experimental groups $(P>0 \cdot 05)$ (Table 3$)$. However, after $60 \mathrm{~d}$ of feeding the low-FM/FO diet, LLv fish (obtained from broodstock fed low LO and fed at 4 months with the $\mathrm{v}$, high in VM and VO) showed the highest body weight, being significantly $(P<0.05)$ higher than that of fish LLf, from the same broodstock but fed the diet $\mathrm{f}$ at 4 months (high in FM and FO) (Table 3). Besides, the growth of LLv fish was also significantly higher than that of fish from Fv or HLv that had been fed the same $\mathrm{v}$, but came from broodstock fed FO or high LO. Thus, the two-way ANOVA analysis of final body weight showed a significant effect of the broodstock diet $(P<0.05)$ and the interaction between broodstock and reminder diet $(P<0 \cdot 01)$. The specific growth rate of LLv fish was significantly higher than that of LLf, denoting the significant effect of the $\mathrm{v}$, as well as higher than Fv and HLv $(P<0.05)$. Thus, the two-way 
Table 2. Primers, RT-PCR reaction efficiencies, and GeneBank accession numbers and reference articles for sequences of target and housekeeping genes

\begin{tabular}{|c|c|c|c|c|}
\hline Genes & Primer sequence $5^{\prime}-3^{\prime}(F)$ and $5^{\prime}-3^{\prime}(R)$ & Efficiency (\%) & GenBank access no. & References \\
\hline$|p|$ & $\begin{array}{l}\text { CGT TGC CAA GTT TGT GAC CTG } \\
\text { AGG GTG TTC TGG TTG TCT GC }\end{array}$ & $98 \cdot 0$ & AY495672 & (68) \\
\hline ppara & TCT CTT CAG CCC ACC ATC CC & & AY590299 & (68) \\
\hline elovl6 & $\begin{array}{l}\text { ATC CCA GCG TGT CGT CTC C } \\
\text { GTG CTG CTC TAC TCC TGG TA } \\
\text { ACG GCA TGG ACC AAG TAG T }\end{array}$ & $102 \cdot 0$ & JX975702 & (68) \\
\hline fads2 & $\begin{array}{l}\text { CGA GAG CCA CAG CAG CAG GGA } \\
\text { CGG CCT GCG CCT GAG CAG TT }\end{array}$ & $109 \cdot 2$ & AY055749 & $(40)$ \\
\hline $\operatorname{cox} 2$ & $\begin{array}{l}\text { GAG TAC TGG AAG CCG AGC AC } \\
\text { GAT ATC ACT GCC GCC TGA GT }\end{array}$ & $107 \cdot 0$ & AM296029 & (69) \\
\hline$c p t 1 b$ & $\begin{array}{l}\text { CCA CCA GCC AGA CTC CAC AG } \\
\text { CAC CAC CAG CAC CCA CAT ATT TAG }\end{array}$ & $98 \cdot 0$ & DQ866821 & (70) \\
\hline$\beta-A c t$ & $\begin{array}{l}\text { TCT GTC TGG ATC GGA GGC TC } \\
\text { AAG CAT TTG CGG TGG ACG }\end{array}$ & $100 \cdot 7^{\star}$ & X89920 & - \\
\hline
\end{tabular}

Ipl, lipoprotein lipase; elovl6, elongation of very long-chain fatty acids protein 6; fads2, fatty acid desaturase 2; cox2, cyclo-oxygenase-2; cpt1, carnitine palmitoyltransferase I; $\beta$-act, $\beta$-actin.

* The average efficiency of housekeeping gene from six RT-PCR runs.

Table 3. Growth performance parameters after 2 months' feeding of very low-fishmeal (5\%) and very low-fish oil (FO) (3\%) diet in 16 -month-old gilthead sea bream (Sparus aurata) originated from broodstock fed linseed oil (LO) as a replacement for FO - 0\% (100\% FO (F)), 60\% (40\% FO-60\% LO (LL)), $80 \%(20 \%$ FO- $80 \%$ LO (HL)) - and fed either a fishmeal- and FO-based diet (f) or a very low-fishmeal (5\%) and very low-FO (3\%) 'reminder' diet (v) for 1 month at 4 months of age

(Mean values and standard deviations; $n 3$ )

\begin{tabular}{|c|c|c|c|c|c|c|c|c|}
\hline \multirow[b]{2}{*}{ Groups } & \multicolumn{2}{|c|}{ Initial body weight (g) } & \multicolumn{2}{|c|}{ Final body weight (g) } & \multicolumn{2}{|c|}{$\operatorname{SGR}(\% / d)^{*}$} & \multicolumn{2}{|c|}{ FCR† } \\
\hline & Mean & SD & Mean & SD & Mean & SD & Mean & SD \\
\hline $\mathrm{Ff}$ & 243.0 & 1.9 & 337.4 & $3 \cdot 3$ & 0.7 & 0.06 & $1.5^{\mathrm{A}}$ & 0.1 \\
\hline LLf & $244 \cdot 1$ & 0.9 & $336 \cdot 3^{\mathrm{B}}$ & $2 \cdot 6$ & $0.6^{\mathrm{B}}$ & 0.03 & $1.7^{\mathrm{B}}$ & $0 \cdot 1$ \\
\hline HLf & 242.5 & $2 \cdot 0$ & 339.6 & $7 \cdot 2$ & 0.7 & 0.05 & 1.6 & 0.1 \\
\hline $\mathrm{Fv}$ & 243.6 & 0.9 & $319.5^{\mathrm{b}}$ & $5 \cdot \overline{5}$ & $0.5^{\mathrm{b}}$ & 0.07 & $1 \cdot 8^{\mathrm{B}, \mathrm{b}}$ & 0.1 \\
\hline LLv & $246 \cdot 4$ & 0.4 & $351 \cdot 3^{\mathrm{A}, \mathrm{a}}$ & 1.2 & $0 \cdot 7^{\mathrm{A}, \mathrm{a}}$ & 0.03 & $1 \cdot 4^{\mathrm{A}, \mathrm{a}}$ & 0.2 \\
\hline HLv & $242 \cdot 3$ & 1.3 & $321 \cdot 3^{\mathrm{b}}$ & 4.0 & $0.6^{\mathrm{b}}$ & 0.07 & $1.9^{\mathrm{b}}$ & 0.2 \\
\hline \multicolumn{9}{|l|}{ Two-way ANOVA } \\
\hline Broodstock diet $(B)$ & \multicolumn{2}{|c|}{ ND } & \multicolumn{2}{|c|}{$P<0.05$} & \multicolumn{2}{|c|}{ ND } & \multicolumn{2}{|c|}{ ND } \\
\hline Reminder diet $(R)$ & \multicolumn{2}{|c|}{ ND } & \multicolumn{2}{|c|}{ ND } & \multicolumn{2}{|c|}{$P<0.05$} & \multirow{2}{*}{\multicolumn{2}{|c|}{ ND }} \\
\hline$B \times R$ & \multicolumn{2}{|c|}{ ND } & \multicolumn{2}{|c|}{$P<0.01$} & \multicolumn{2}{|c|}{$P<0.05$} & & $P<0.01$ \\
\hline
\end{tabular}

SGR, specific growth rate; FCR, feed conversion ratio; ND, no difference.

$A, B$ Mean values with unlike superscript letters were significantly different between fish fed for $v$ diets during the first nutritional challenge (reminder) coming from the same parental feeding. ${ }^{a, b}$ Mean values with unlike superscript letters were significantly different between fish coming from different parental feeding and fed the same diet during the first nutritional challenge (reminder) $(P<0.05)$.

* $\operatorname{SGR}(\% / \mathrm{d})=(\operatorname{Ln}($ final weight $(\mathrm{g}))-\operatorname{Ln}($ initial weight $(\mathrm{g}))) /($ number of days $) \times 100$.

$\dagger \mathrm{FCR}=($ total weight of consumed feed $(\mathrm{g})) /($ weight gain $(\mathrm{g})$ ).

ANOVA showed the significant effect of the reminder diet at 4 months as well as the interaction between broodstock and reminder diet $(P<0.05)$. Regarding feed conversion, the best values were also obtained for fish in the LLv, Fv or HLv group. For fish coming from broodstock fed $\mathrm{FO}$, the feed conversion ratio (FCR) was better when fish had been fed FO at 4 months (Ff) than when fed diet v (Fv). The two-way ANOVA showed a strong interaction between broodstock and reminder diets $(P<0 \cdot 01)$.

\section{Biochemical composition}

At the end of the study, protein, lipid and ash contents of liver or muscle were similar $(P>0.05)$ (Table 4). However, liver fatty acid composition was significantly affected by broodstock or reminder diets as well as by their interaction (Table 5). For instance, LO increase in broodstock diet significantly reduced liver contents on $16: 4 n-3$, a product of EPA $\beta$-oxidation, and increased $16: 3 n-1$ or
$18: 0$, whereas the interaction of broodstock and reminder diets affected the ratios 18:0:16:0 and 18:1:16:1, indicators of elovl 6 activity, and the related ratio 16:1:16:0 (Table 5). The fads2 products $20: 3 n-6$ and $20: 4 n-3$ were significantly reduced by the reminder diet $(P=0 \cdot 018)$ and its interaction with the broodstock diet $(P=0 \cdot 015)$, respectively, whereas $20: 4 n-6,20: 5 n-3$ and $22: 6 n-3$ tended to be higher in offspring fed the reminder diet, but were not significantly different $(P=0 \cdot 17)$ (Table 5). Muscle fatty acid composition did not differ significantly among the different experimental groups $(P>0.05)$ (Table 6).

\section{Gene expression}

Reduction of LC-PUFA and increase in ALA and LA in broodstock diets lead to a significant $(P<0.001)$ down-regulation of hepatic $l p l$ (Fig. 2), which was significantly $(P<0.01)$ emphasised by feeding the 4-month-old juveniles the $\mathrm{v}$ diet, based on 
Table 4. Biochemical composition of liver and muscle tissue after 2 months' feeding with a very low-fishmeal ( $5 \%)$ and very low-fish oil (FO) ( $3 \%)$ diet in 16 -month-old gilthead sea bream (Sparus aurata) originated from broodstock fed linseed oil (LO) as a replacement for FO - 0\% (100\% FO (F)), $60 \%$ (40\% FO-60\% LO (LL)), $80 \%$ (20\% FO-80\% LO (HL)) - and fed either a fishmeal- and FO-based diet (f) or a very low-fishmeal (5\%) and very low-FO $(3 \%)$ 'reminder' diet (v) for 1 month at 4 months of age

(Mean values and standard deviations; $n 3$ )

\begin{tabular}{|c|c|c|c|c|c|c|c|c|}
\hline \multirow[b]{2}{*}{ Groups } & \multicolumn{2}{|c|}{ Moisture (\%) } & \multicolumn{2}{|c|}{ Protein (\%) } & \multicolumn{2}{|c|}{ Lipids (\%) } & \multicolumn{2}{|c|}{ Ash (\%) } \\
\hline & Mean & SD & Mean & SD & Mean & $\mathrm{SD}$ & Mean & SD \\
\hline \multicolumn{9}{|l|}{ Liver* } \\
\hline $\mathrm{Ff}$ & $64 \cdot 2$ & $2 \cdot 0$ & 11.1 & 0.3 & 14.9 & 3.0 & 2.5 & 0.5 \\
\hline LLf & $66 \cdot 6$ & 5.9 & $10 \cdot 1$ & $2 \cdot 4$ & $12 \cdot 9$ & 5.9 & $2 \cdot 7$ & 1.2 \\
\hline HLf & $66 \cdot 5$ & 0.1 & $12 \cdot 1$ & 0.4 & $11 \cdot 7$ & $1 \cdot 8$ & $2 \cdot 9$ & 0.3 \\
\hline Fv & 66.6 & 4.2 & 11.2 & 1.3 & $11 \cdot 0$ & $2 \cdot 2$ & 2.9 & 0.4 \\
\hline LLV & $68 \cdot 4$ & $2 \cdot 8$ & $12 \cdot 2$ & 1.4 & $10 \cdot 9$ & 4.9 & $2 \cdot 7$ & 0.8 \\
\hline HLV & $67 \cdot 1$ & $4 \cdot 1$ & $10 \cdot 7$ & 1.3 & $12 \cdot 7$ & $4 \cdot 4$ & $2 \cdot 4$ & 0.1 \\
\hline \multicolumn{9}{|l|}{ Muscle* } \\
\hline $\mathrm{Ff}$ & $72 \cdot 3$ & 0.1 & 21.6 & 0.1 & $5 \cdot 1$ & 0.5 & 1.4 & 0.1 \\
\hline LLf & $72 \cdot 7$ & 0.5 & 20.6 & 0.9 & $5 \cdot 2$ & 0.7 & 1.4 & 0.1 \\
\hline HLf & $72 \cdot 5$ & 0.8 & $21 \cdot 3$ & 0.2 & $5 \cdot 4$ & $1 \cdot 1$ & 1.4 & 0.1 \\
\hline $\mathrm{Fv}$ & 73.0 & 0.1 & $21 \cdot 3$ & 0.3 & 4.7 & 0.2 & 1.5 & 0.1 \\
\hline LLv & 72.5 & 1.0 & 21.3 & 0.4 & $5 \cdot 2$ & 0.5 & 1.5 & 0.1 \\
\hline HLV & 72.9 & 0.1 & 21.4 & 0.2 & 4.9 & 0.5 & 1.4 & 0.1 \\
\hline
\end{tabular}

* No significant differences were found for broodstock diet $(P>0.05)$, reminder diet $(P>0.05)$ and interaction of these two factors $(P>0.05)$ using the two-way ANOVA analysis.

plant ingredients and with low LC-PUFA and high ALA and LA contents. Thus, the lowest relative expression of $l p l$ was found in HLv and HLf fish. Similarly, the origin of the fish based on different broodstock diets significantly $(P<0 \cdot 01)$ downregulated hepatic elovl6 (Fig. 2), with the lowest relative expression of elovl6 found in LLv and HLf fish. Besides, elovl6 expression was significantly correlated to liver contents of 18:1:16:1 $(r 0.89)$ and 18:0:16:0 $(r 0.89)$, ratios of product: substrate of elovl6 activity. There was no significant effect of either the broodstock or the reminder diet on hepatic expression of fads2 (Fig. 2), but their values were positively correlated to hepatic levels of $18: 4 n-3(r 0.86)$ and $18: 3 n-6(r 0.8)$, products of the fads 2 activity, as well as to the end desaturation products 20:5n-3 ( $r$ 0.98), 22:6n-3 $(r$ 0.95) and 22:5n-6 ( $r$ 0.95). Besides, fads 2 expression values were negatively correlated $(r-0.52)$ to elovl6. Regarding fatty acid catabolism biomarkers, reduction of LC-PUFA and increase in ALA and LA acids in broodstock diets lead to a significant $(P<0.001)$ downregulation of hepatic cpt1b (Fig. 2), which was significantly $(P<0.05)$ emphasised by the reminder diet. Moreover, the relative expression of $c p t 1 b$ was highly correlated to $18: 1 n-9$ ( $r$ 0.82) and negatively correlated to 20:5n-3 ( $r-0.62)$. No significant differences were found in the relative expression of ppara or cox 2 , which were negatively correlated $(r-0.57$ and $r-0 \cdot 73$, respectively) to $c p t 1 b$ expression.

The overall response showed similar trends for $l p l, c p t 1 b$ and elovl6 expressions, whose values showed a high correlation in their relative gene expression between $l p l$ and elovl6 ( $r$ 0.52), cpt1b and elovl6 ( $r$ 0.72) and lpl and cpt1b ( $r$ 0.74).

\section{Discussion}

In animal production, nutritional programming can be useful to improve offspring adaptation to farm conditions ${ }^{(74,75)}$. As the limited availability of FM and FO is the main constraint in fish production, modulation of offspring phenotype through parental feeding for an improved utilisation of low-FM and low-FO diets can have important advantages ${ }^{(31)}$. Previous studies in gilthead sea bream have demonstrated that it is possible to improve low-FM and low-FO feed utilisation in the offspring coming from broodstock fed with increased substitution of FO with $\mathrm{LO}^{(45)}$. This adaptation included the regulation of expression of genes for key metabolic enzymes in the liver such as fads $2^{(45)}$ or glucocorticoid receptor ( $g r$ ) (S Turkmen et al., unpublished results). However, the persistence of these phenotypic or metabolic changes later in life had not been studied yet. The present study shows that replacement of parental feeding with moderate-FO with LO combined with juvenile feeding with low-FM and low-FO diets improves offspring growth and feed utilisation of low-FM/FO diets even when they are 16 months old: that is, when they are on the verge of their first reproductive season. Thus, among fish fed the low-FM/FO diet during the juvenile stages, those obtained from parents fed moderate LO levels showed the highest growth, denoting the persistent effect of parental nutrition. However, higher LO levels ( $80 \%$ replacement of FO) in broodstock diets did not improve the growth of 16-month-old offspring, in agreement with previous studies ${ }^{(45)}$. Thus, feeding broodstock with this high-LO diet markedly reduced spawning quality, larval survival and larval and juvenile growth ${ }^{(45)}$, as a consequence of the deleterious effects of very low $n$ - 3 HUFA levels in broodstock $\operatorname{diets}^{(47)}$. The present study demonstrated the persistence of these negative effects of early EFA deficiencies during offspring life. On the contrary, $60 \%$-FO substitution with LO in sea bream broodstock diets did not negatively affect spawning quality or larval growth and produced 4-month-old juveniles with a better ability to utilise low-FM/FO diets ${ }^{(45)}$, in agreement with the present study.

The above-mentioned growth improvement in 16-month-old fish obtained from broodstock fed moderate LO levels and the reminder low-FM/FO diet at 4 months of age was also 
Table 5. \% Total fatty acids (FA) of livers after 2 months' feeding a very low-fishmeal (5\%) and very low-fish oil (FO) ( $3 \%$ ) diet in 16 -month-old gilthead sea bream (Sparus aurata) originated from broodstock fed linseed oil (LO) as a replacement for FO - 0\% (100\% FO (F)), $60 \%$ (40\% FO-60\% LO (LL)), $80 \%$ (20\% FO-80\% LO (HL)) - and fed either a fishmeal- and FO-based diet (f) or a very low-fishmeal (5\%) and very low-FO (3\%) 'reminder' diet (v) for 1 month at 4 months of age

(Mean values and standard deviations; $n$ 3)

\begin{tabular}{|c|c|c|c|c|c|c|c|c|c|c|c|c|c|c|c|}
\hline \multirow[b]{3}{*}{ FA (\%) } & \multicolumn{12}{|c|}{ Groups } & & & \\
\hline & \multicolumn{2}{|c|}{$\mathrm{Ff}$} & \multicolumn{2}{|c|}{ LLf } & \multicolumn{2}{|c|}{ HLf } & \multicolumn{2}{|c|}{$\mathrm{Fv}$} & \multicolumn{2}{|c|}{ LLv } & \multicolumn{2}{|c|}{ HLv } & \multicolumn{3}{|c|}{ Two-way ANOVA } \\
\hline & Mean & $\mathrm{SD}$ & Mean & $\mathrm{SD}$ & Mean & $\mathrm{SD}$ & Mean & SD & Mean & $\mathrm{SD}$ & Mean & $\mathrm{SD}$ & $B$ & $R$ & $B \times R$ \\
\hline $14: 0$ & $4 \cdot 17$ & 0.53 & $4 \cdot 68$ & 0.33 & $5 \cdot 29$ & 0.72 & $4 \cdot 86$ & 0.59 & 4.89 & 0.11 & $4 \cdot 68$ & 0.90 & 0.403 & 0.732 & 0.201 \\
\hline $14: 1 n-7$ & 0.05 & 0.01 & 0.05 & 0.00 & 0.05 & 0.00 & 0.05 & 0.01 & 0.05 & 0.00 & 0.04 & 0.00 & 0.745 & 0.477 & 0.480 \\
\hline $14: 1 n-5$ & 0.06 & 0.00 & 0.07 & 0.02 & 0.05 & 0.01 & 0.07 & 0.02 & 0.06 & 0.01 & 0.06 & 0.01 & 0.581 & 0.485 & 0.206 \\
\hline $15: 0$ & 0.16 & 0.01 & 0.20 & 0.05 & 0.17 & 0.03 & 0.18 & 0.03 & 0.18 & 0.02 & 0.19 & 0.00 & 0.506 & 0.409 & 0.333 \\
\hline $15: 1 n-5$ & 0.03 & 0.00 & 0.03 & 0.00 & 0.03 & 0.00 & 0.03 & 0.00 & 0.03 & 0.00 & 0.03 & 0.00 & 0.625 & 0.220 & 0.654 \\
\hline $16: 0$ iso & 0.03 & 0.00 & 0.04 & 0.01 & 0.03 & 0.00 & 0.03 & 0.00 & 0.03 & 0.00 & 0.04 & 0.01 & 0.888 & 0.851 & 0.241 \\
\hline $16: 0$ & $12 \cdot 61$ & 0.93 & $14 \cdot 33$ & 1.96 & $14 \cdot 81$ & 0.83 & 13.92 & 0.71 & 14.77 & 0.30 & 13.63 & 0.64 & 0.141 & 0.717 & 0.200 \\
\hline $16: 1 n-7$ & 4.51 & 0.15 & 4.89 & 0.84 & 4.00 & 0.07 & 4.76 & 0.54 & $4 \cdot 37$ & 0.10 & $4 \cdot 70$ & 0.69 & 0.557 & 0.545 & 0.148 \\
\hline $16: 1 n-5$ & 0.10 & 0.01 & 0.11 & 0.01 & 0.09 & 0.00 & 0.10 & 0.01 & 0.10 & 0.00 & 0.11 & 0.02 & 0.476 & 0.401 & 0.038 \\
\hline $16: 2 n-6$ & 0.00 & 0.00 & 0.01 & 0.00 & 0.00 & 0.00 & 0.00 & 0.00 & 0.00 & 0.00 & 0.01 & 0.00 & 0.230 & 0.735 & 0.040 \\
\hline $16: 2 n-4$ & 0.21 & 0.00 & 0.24 & 0.05 & 0.17 & 0.02 & 0.23 & 0.05 & 0.21 & 0.02 & 0.23 & 0.00 & 0.542 & 0.329 & 0.071 \\
\hline $17: 0$ & 0.19 & 0.00 & 0.20 & 0.01 & 0.15 & 0.01 & 0.20 & 0.04 & 0.18 & 0.01 & 0.20 & 0.01 & 0.259 & 0.165 & 0.112 \\
\hline $16: 3 n-4$ & 0.18 & 0.01 & 0.18 & 0.01 & 0.16 & 0.00 & 0.17 & 0.00 & 0.16 & 0.00 & 0.17 & 0.03 & 0.158 & 0.208 & 0.058 \\
\hline $16: 3 n-3$ & 0.05 & 0.00 & 0.06 & 0.02 & 0.05 & 0.00 & 0.05 & 0.00 & 0.05 & 0.00 & 0.06 & 0.01 & 0.805 & 0.655 & 0.287 \\
\hline $16: 3 n-1$ & 0.01 & 0.00 & 0.02 & 0.00 & 0.02 & 0.00 & 0.01 & 0.00 & 0.02 & 0.00 & 0.01 & 0.00 & 0.015 & 0.787 & 0.600 \\
\hline $16: 4 n-3$ & 0.12 & 0.01 & 0.11 & 0.01 & 0.07 & 0.01 & 0.12 & 0.04 & 0.11 & 0.01 & 0.09 & 0.00 & 0.037 & 0.609 & 0.437 \\
\hline $16: 4 n-1$ & 0.00 & 0.00 & 0.00 & 0.00 & 0.00 & 0.00 & 0.00 & 0.00 & 0.00 & 0.00 & 0.00 & 0.00 & 0.441 & 0.377 & 0.441 \\
\hline $18: 0$ & $4 \cdot 28$ & 0.26 & $4 \cdot 15$ & 0.30 & 4.97 & 0.22 & 3.88 & 0.37 & 4.50 & 0.32 & $4 \cdot 41$ & 0.42 & 0.026 & 0.206 & 0.068 \\
\hline $18: 1 n-9$ & 31.93 & 1.02 & 29.93 & 2.77 & 32.06 & 0.48 & $30 \cdot 14$ & 3.42 & 29.60 & 2.52 & $30 \cdot 10$ & $2 \cdot 38$ & 0.571 & 0.259 & 0.812 \\
\hline $18: 1 n-7$ & $2 \cdot 72$ & 0.06 & 2.85 & 0.18 & 2.66 & 0.06 & 2.68 & 0.15 & $2 \cdot 64$ & 0.07 & 2.88 & 0.26 & 0.671 & 0.921 & 0.065 \\
\hline $18: 1 n-5$ & 0.12 & 0.01 & 0.13 & 0.03 & 0.09 & 0.01 & 0.12 & 0.03 & 0.10 & 0.00 & 0.13 & 0.02 & 0.762 & 0.911 & 0.045 \\
\hline $18: 2 n-9$ & 0.61 & 0.13 & 0.57 & 0.28 & 0.44 & 0.02 & 0.62 & 0.07 & 0.53 & 0.19 & 0.55 & 0.27 & 0.546 & 0.791 & 0.793 \\
\hline $18: 2 n-6$ & $13 \cdot 10$ & 0.47 & 12.92 & $1 \cdot 26$ & $13 \cdot 87$ & 0.81 & 12.93 & 1.02 & $12 \cdot 86$ & 0.18 & 12.93 & 0.95 & 0.617 & 0.375 & 0.672 \\
\hline $18: 2 n-4$ & 0.15 & 0.01 & 0.16 & 0.01 & 0.13 & 0.00 & 0.14 & 0.02 & 0.14 & 0.01 & 0.16 & 0.02 & 0.943 & 0.653 & 0.047 \\
\hline $18: 3 n-6$ & 1.08 & 0.21 & 1.04 & 0.45 & 0.78 & 0.06 & 1.08 & 0.08 & 0.91 & 0.21 & 0.93 & 0.31 & 0.375 & 0.944 & 0.665 \\
\hline $18: 3 n-4$ & 0.15 & 0.00 & 0.15 & 0.01 & 0.12 & 0.00 & 0.15 & 0.02 & 0.13 & 0.01 & 0.14 & 0.02 & 0.063 & 0.743 & 0.216 \\
\hline $18: 3 n-3$ & $5 \cdot 32$ & 0.36 & 5.03 & $1 \cdot 19$ & $5 \cdot 74$ & 0.28 & $5 \cdot 15$ & 0.78 & $5 \cdot 31$ & 0.06 & 5.03 & $1 \cdot 16$ & 0.891 & 0.577 & 0.556 \\
\hline $18: 3 n-1$ & 0.01 & 0.00 & 0.01 & 0.00 & 0.00 & 0.00 & 0.01 & 0.00 & 0.01 & 0.00 & 0.01 & 0.00 & 0.392 & 0.491 & 0.173 \\
\hline $18: 4 n-3$ & 0.72 & 0.07 & 0.75 & 0.25 & 0.55 & 0.03 & 0.77 & 0.13 & 0.66 & 0.08 & 0.66 & 0.02 & 0.222 & 0.765 & 0.444 \\
\hline $18: 4 n-1$ & 0.14 & 0.01 & 0.14 & 0.01 & 0.11 & 0.01 & 0.12 & 0.02 & 0.12 & 0.00 & 0.14 & 0.00 & 0.323 & 0.671 & 0.039 \\
\hline $20: 0$ & 0.12 & 0.01 & 0.13 & 0.03 & 0.13 & 0.02 & 0.12 & 0.01 & 0.14 & 0.01 & 0.14 & 0.02 & 0.308 & 0.764 & 0.970 \\
\hline $20: 1 n-9$ & 0.16 & 0.02 & 0.18 & 0.06 & 0.11 & 0.02 & 0.18 & 0.07 & 0.15 & 0.02 & 0.19 & 0.05 & 0.720 & 0.352 & 0.141 \\
\hline $20: 1 n-7$ & 1.37 & 0.11 & 1.41 & 0.42 & $1 \cdot 28$ & 0.07 & $1 \cdot 28$ & 0.01 & 1.33 & 0.12 & 1.40 & 0.04 & 0.903 & 0.869 & 0.629 \\
\hline $20: 1 n-5$ & 0.13 & 0.01 & 0.14 & 0.03 & 0.11 & 0.01 & 0.12 & 0.01 & 0.12 & 0.01 & 0.14 & 0.02 & 0.803 & 0.835 & 0.232 \\
\hline $20: 2 n-9$ & 0.78 & 0.07 & 0.53 & 0.09 & 0.57 & 0.08 & 0.55 & 0.18 & 0.55 & 0.06 & 0.48 & $0 \cdot 10$ & 0.098 & 0.068 & 0.160 \\
\hline $20: 2 n-6$ & 0.59 & 0.08 & 0.54 & 0.04 & 0.63 & 0.03 & 0.49 & 0.10 & 0.55 & 0.06 & 0.56 & 0.06 & 0.385 & 0.156 & 0.314 \\
\hline $20: 3 n-9$ & 0.02 & 0.02 & 0.02 & 0.01 & 0.02 & 0.01 & 0.02 & 0.01 & 0.02 & 0.00 & 0.02 & 0.01 & 0.709 & 0.533 & 0.409 \\
\hline $20: 3 n-6$ & 0.52 & 0.08 & 0.39 & 0.06 & 0.37 & 0.04 & 0.34 & 0.07 & 0.35 & 0.02 & 0.37 & 0.04 & 0.144 & $0.018^{*}$ & $0.048^{*}$ \\
\hline $20: 4 n-6$ & 0.41 & 0.06 & 0.50 & 0.15 & 0.42 & 0.05 & 0.47 & 0.15 & 0.57 & 0.18 & 0.49 & 0.07 & 0.450 & 0.312 & 0.998 \\
\hline $20: 3 n-3$ & 0.45 & 0.05 & 0.39 & 0.03 & 0.47 & 0.03 & 0.37 & 0.09 & 0.42 & 0.04 & 0.43 & 0.09 & 0.448 & 0.277 & 0.308 \\
\hline $20: 4 n-3$ & 0.72 & 0.08 & 0.64 & 0.06 & 0.51 & 0.04 & 0.59 & 0.09 & 0.56 & 0.05 & 0.64 & 0.06 & 0.136 & 0.421 & $0.015^{\star}$ \\
\hline $20: 5 n-3$ & 2.85 & 0.25 & 3.01 & 0.28 & $2 \cdot 16$ & 0.23 & 3.09 & $1 \cdot 22$ & $3 \cdot 11$ & 0.48 & $3 \cdot 10$ & 0.02 & 0.489 & 0.168 & 0.491 \\
\hline $22: 1 n-11$ & 0.48 & $0 \cdot 10$ & 0.61 & 0.33 & 0.33 & 0.09 & 0.52 & 0.11 & 0.52 & 0.10 & 0.57 & 0.01 & 0.525 & 0.479 & 0.301 \\
\hline $22: 1 n-9$ & 0.40 & 0.01 & 0.43 & 0.10 & 0.40 & 0.04 & 0.38 & 0.00 & 0.41 & 0.03 & 0.43 & 0.01 & 0.576 & 0.943 & 0.618 \\
\hline $22: 4 n-6$ & 0.08 & 0.01 & 0.08 & 0.02 & 0.06 & 0.00 & 0.07 & 0.02 & 0.07 & 0.01 & 0.09 & 0.01 & 0.875 & 0.301 & 0.118 \\
\hline $22: 5 n-6$ & 0.07 & 0.01 & 0.08 & 0.01 & 0.06 & 0.01 & 0.07 & 0.03 & 0.08 & 0.01 & 0.08 & 0.00 & 0.587 & 0.217 & 0.514 \\
\hline $22: 5 n-3$ & $2 \cdot 25$ & 0.47 & 1.98 & 0.21 & 1.36 & 0.24 & 2.06 & 0.91 & 1.79 & 0.21 & 2.25 & 0.28 & 0.457 & 0.487 & 0.152 \\
\hline $22: 6 n-3$ & $5 \cdot 78$ & 1.09 & 5.90 & $1 \cdot 15$ & 4.35 & 0.66 & 6.67 & 3.09 & 6.55 & 1.37 & $6 \cdot 33$ & 0.35 & 0.612 & 0.168 & 0.785 \\
\hline$\sum$ SFA† & 21.55 & $1 \cdot 23$ & $23 \cdot 73$ & 2.49 & $25 \cdot 55$ & 0.81 & $23 \cdot 21$ & 1.48 & $24 \cdot 70$ & 0.62 & $23 \cdot 28$ & 1.97 & 0.088 & 0.876 & 0.135 \\
\hline$\sum$ MUFA & 42.06 & 0.91 & $40 \cdot 83$ & 0.77 & $41 \cdot 26$ & 0.71 & $40 \cdot 44$ & 2.58 & 39.47 & $2 \cdot 28$ & $40 \cdot 78$ & 3.51 & 0.592 & 0.243 & 0.882 \\
\hline$\sum n-6 \S$ & $15 \cdot 84$ & 0.32 & $15 \cdot 55$ & 1.54 & $16 \cdot 19$ & 0.77 & $15 \cdot 47$ & 0.92 & $15 \cdot 39$ & 0.19 & $15 \cdot 45$ & 0.71 & 0.806 & 0.343 & 0.859 \\
\hline$\sum n-3 \|$ & $18 \cdot 28$ & 1.56 & $17 \cdot 91$ & 0.39 & $15 \cdot 27$ & 1.25 & $18 \cdot 88$ & 4.61 & $18 \cdot 58$ & 1.98 & $18 \cdot 60$ & 1.25 & 0.510 & 0.209 & 0.582 \\
\hline$c 16: 1: c 16$ & 0.36 & 0.03 & 0.34 & 0.01 & 0.27 & 0.01 & 0.34 & 0.05 & 0.30 & 0.01 & 0.35 & 0.07 & 0.122 & 0.748 & $0.036^{*}$ \\
\hline $18: 0: 16: 0$ & 0.34 & 0.04 & 0.29 & 0.02 & 0.34 & 0.02 & 0.28 & 0.02 & 0.30 & 0.02 & 0.32 & 0.02 & 0.204 & 0.089 & 0.064 \\
\hline $18: 1: 16: 1$ & 1.18 & 0.06 & $1 \cdot 20$ & 0.11 & 1.02 & 0.13 & 1.19 & 0.22 & 0.94 & 0.05 & 0.92 & 0.02 & 0.275 & 0.633 & $0.047^{*}$ \\
\hline
\end{tabular}

$B$, broodstock; $R$, reminder; $B \times R$, interaction of broodstock and reminder.

* $P$ values under 0.05

† $\sum$ SFA include $14: 0,15: 0,16: 0,17: 0,18: 0$ and $20: 0$.

‡ $\sum$ MUFA include $14: 1 n-7,14: 1 n-5,15: 1 n-5,16: 1 n-5,18: 1 n-9,18: 1 n-7,18: 1 n-5,20: 1 n-9,20: 1 n-7,20: 1 n-5,22: 1 n-11$ and $22: 1 n-9$.

$\S \sum n-6: n-6$ series PUFA include $16: 2 n-6,18: 2 n-6,18: 3 n-6,20: 2 n-6,20: 3 n-6,20: 4 n-6,22: 4 n-6,22: 5 n-6$.

II $\sum n-3: n-3$ series PUFA include $16: 3 n-3,16: 4 n-3,18: 3 n-3,18: 4 n-3,20: 3 n-3,20: 4 n-3,20: 5 n-3,22: 5 n-3,22: 6 n-3$. 
Table 6. \% Total fatty acids of muscle after 2 months' feeding of a very low-fishmeal (5\%) and very low-fish oil (FO) (3\%) diet in 16-month-old gilthead sea bream (Sparus aurata) originated from broodstock fed linseed oil (LO) as a replacement for fish oil - 0\% (100\% FO (F)), 60\% (40\% FO-60\% LO (LL)), $80 \%(20 \%$ FO-80 \% LO (HL)) - and fed either a fishmeal- and FO-based diet (f) or a very low-fishmeal (5\%) and very low-FO (3\%) 'reminder' diet (v) for 1 month at 4 months of age

(Mean values and standard deviations; $n$ 3)

\begin{tabular}{|c|c|c|c|c|c|c|c|c|c|c|c|c|}
\hline \multirow[b]{3}{*}{$\mathrm{FA}(\%)^{*}$} & \multicolumn{12}{|c|}{ Groups } \\
\hline & \multicolumn{2}{|c|}{$\mathrm{Ff}$} & \multicolumn{2}{|c|}{ LLf } & \multicolumn{2}{|c|}{ HLf } & \multicolumn{2}{|c|}{ Fv } & \multicolumn{2}{|c|}{ LLv } & \multicolumn{2}{|c|}{ HLv } \\
\hline & Mean & SD & Mean & SD & Mean & SD & Mean & $S D$ & Mean & SD & Mean & $\mathrm{SD}$ \\
\hline $14: 0$ & 4.83 & 0.15 & 4.90 & 0.15 & $5 \cdot 17$ & 0.15 & 4.99 & 0.33 & 4.98 & 0.03 & 4.97 & 0.35 \\
\hline $14: 1 n-7$ & 0.08 & 0.00 & 0.08 & 0.00 & 0.08 & 0.00 & 0.08 & 0.00 & 0.07 & 0.00 & 0.08 & 0.00 \\
\hline $14: 1 n-5$ & 0.08 & 0.00 & 0.09 & 0.03 & 0.08 & 0.02 & 0.09 & 0.01 & 0.08 & 0.00 & 0.08 & 0.01 \\
\hline $15: 0$ & 0.21 & 0.01 & 0.23 & 0.01 & 0.21 & 0.01 & 0.22 & 0.02 & 0.22 & 0.00 & 0.22 & 0.02 \\
\hline $15: 1 n-5$ & 0.02 & 0.00 & 0.03 & 0.00 & 0.03 & 0.00 & 0.02 & 0.01 & 0.03 & 0.00 & 0.03 & 0.00 \\
\hline 16 : 0iso & 0.03 & 0.00 & 0.03 & 0.00 & 0.03 & 0.00 & 0.03 & 0.00 & 0.03 & 0.00 & 0.03 & 0.01 \\
\hline $16: 0$ & 14.69 & 0.42 & 15.03 & 0.41 & 14.52 & 0.21 & $15 \cdot 03$ & 0.12 & $15 \cdot 18$ & 0.31 & 14.88 & 0.48 \\
\hline $16: 1 n-7$ & 4.89 & 0.31 & $5 \cdot 12$ & 0.18 & 4.51 & 0.14 & 4.92 & 0.64 & 4.89 & 0.36 & 4.87 & 0.72 \\
\hline $16: 1 n-5$ & 0.08 & 0.00 & 0.09 & 0.00 & 0.08 & 0.00 & 0.08 & 0.01 & 0.08 & 0.01 & 0.08 & 0.01 \\
\hline $16: 2 n-6$ & 0.05 & 0.04 & 0.01 & 0.00 & 0.01 & 0.00 & 0.01 & 0.00 & 0.01 & 0.00 & 0.01 & 0.00 \\
\hline $16: 2 n-4$ & 0.36 & 0.07 & 0.33 & 0.02 & 0.29 & 0.01 & 0.31 & 0.05 & 0.31 & 0.01 & 0.31 & 0.04 \\
\hline $17: 0$ & 0.28 & 0.03 & 0.30 & 0.01 & 0.27 & 0.00 & 0.29 & 0.04 & 0.28 & 0.01 & 0.29 & 0.03 \\
\hline $16: 3 n-4$ & 0.14 & 0.00 & 0.14 & 0.00 & 0.14 & 0.01 & 0.14 & 0.01 & 0.14 & 0.00 & 0.14 & 0.01 \\
\hline $16: 3 n-3$ & 0.05 & 0.00 & 0.05 & 0.01 & 0.04 & 0.00 & 0.05 & 0.02 & 0.04 & 0.01 & 0.05 & 0.01 \\
\hline $16: 3 n-1$ & 0.05 & 0.02 & 0.07 & 0.01 & 0.07 & 0.01 & 0.09 & 0.01 & 0.07 & 0.00 & 0.08 & 0.02 \\
\hline $16: 4 n-3$ & 0.35 & 0.11 & 0.34 & 0.03 & 0.31 & 0.01 & 0.33 & 0.06 & 0.34 & 0.01 & 0.30 & 0.09 \\
\hline $16: 4 n-1$ & 0.01 & 0.00 & 0.01 & 0.00 & 0.01 & 0.00 & 0.01 & 0.00 & 0.01 & 0.00 & 0.01 & 0.01 \\
\hline $18: 0$ & 3.50 & 0.04 & 3.45 & 0.11 & 3.55 & 0.11 & 3.55 & 0.07 & 3.53 & 0.00 & 3.61 & 0.10 \\
\hline $18: 1 n-9$ & $27 \cdot 27$ & 0.21 & $27 \cdot 23$ & 0.92 & 28.47 & 0.99 & $27 \cdot 23$ & 1.37 & $27 \cdot 77$ & 0.28 & 27.66 & 1.00 \\
\hline $18: 1 n-7$ & 2.85 & 0.06 & 2.90 & 0.01 & 2.74 & 0.04 & 2.84 & 0.16 & 2.82 & 0.08 & 2.84 & 0.14 \\
\hline $18: 1 n-5$ & 0.39 & 0.45 & 0.13 & 0.01 & 0.11 & 0.01 & 0.13 & 0.02 & 0.12 & 0.01 & 0.13 & 0.02 \\
\hline $18: 2 n-9$ & 0.22 & 0.02 & 0.25 & 0.06 & 0.22 & 0.01 & 0.24 & 0.02 & 0.24 & 0.02 & 0.22 & 0.02 \\
\hline $18: 2 n-6$ & 11.52 & 0.40 & 11.46 & 0.55 & 12.77 & 0.49 & 11.62 & $1 \cdot 36$ & 11.74 & 0.62 & $11 . \overline{79}$ & 1.59 \\
\hline $18: 2 n-4$ & 0.13 & 0.01 & 0.14 & 0.00 & 0.13 & 0.01 & 0.13 & 0.01 & 0.13 & 0.01 & 0.14 & 0.01 \\
\hline $18: 3 n-6$ & 0.35 & 0.05 & 0.36 & 0.05 & 0.33 & 0.01 & 0.35 & 0.03 & 0.34 & 0.02 & 0.32 & 0.00 \\
\hline $18: 3 n-4$ & 0.15 & 0.01 & 0.14 & 0.00 & 0.13 & 0.00 & 0.15 & 0.01 & 0.13 & 0.01 & 0.14 & 0.01 \\
\hline $18: 3 n-3$ & $5 \cdot 11$ & $1 \cdot 11$ & 4.53 & 0.51 & 5.48 & 0.47 & 4.57 & $1 \cdot 16$ & 4.76 & 0.40 & 4.75 & 1.18 \\
\hline $18: 3 n-1$ & 0.18 & 0.30 & 0.01 & 0.00 & 0.01 & 0.00 & 0.01 & 0.00 & 0.01 & 0.00 & 0.01 & 0.00 \\
\hline $18: 4 n-3$ & 0.69 & 0.04 & 0.73 & 0.03 & 0.64 & 0.03 & 0.69 & 0.07 & 0.70 & 0.05 & 0.67 & 0.06 \\
\hline $18: 4 n-1$ & 0.22 & 0.13 & 0.14 & 0.00 & 0.14 & 0.01 & 0.13 & 0.01 & 0.14 & 0.01 & 0.15 & 0.01 \\
\hline $20: 0$ & 0.24 & 0.01 & 0.24 & 0.01 & 0.24 & 0.01 & 0.24 & 0.00 & 0.24 & 0.01 & 0.24 & 0.00 \\
\hline $20: 1 n-9$ & 0.28 & 0.02 & 0.29 & 0.03 & 0.25 & 0.03 & 0.31 & 0.09 & 0.28 & 0.03 & 0.28 & 0.07 \\
\hline $20: 1 n-7$ & 2.36 & 0.13 & 2.44 & 0.24 & $2 \cdot 19$ & 0.10 & 2.43 & 0.38 & 2.37 & 0.11 & 2.35 & 0.34 \\
\hline $20: 1 n-5$ & 0.16 & 0.01 & 0.17 & 0.01 & 0.16 & 0.01 & 0.17 & 0.02 & 0.16 & 0.01 & 0.16 & 0.02 \\
\hline $20: 2 n-9$ & 0.31 & 0.01 & 0.31 & 0.02 & 0.31 & 0.03 & 0.30 & 0.02 & 0.30 & 0.01 & 0.28 & 0.01 \\
\hline $20: 2 n-6$ & 0.60 & 0.29 & 0.42 & 0.02 & 0.45 & 0.00 & 0.42 & 0.02 & 0.42 & 0.00 & 0.43 & 0.02 \\
\hline $20: 3 n-9$ & 0.03 & 0.01 & 0.03 & 0.01 & 0.05 & 0.01 & 0.04 & 0.02 & 0.04 & 0.03 & 0.06 & 0.03 \\
\hline $20: 3 n-6$ & 0.23 & 0.00 & 0.22 & 0.01 & 0.24 & 0.02 & 0.22 & 0.01 & 0.21 & 0.01 & 0.21 & 0.03 \\
\hline $20: 4 n-6$ & 0.46 & 0.04 & 0.46 & 0.04 & 0.42 & 0.06 & 0.46 & 0.06 & 0.44 & 0.00 & 0.46 & 0.05 \\
\hline $20: 3 n-3$ & 0.33 & 0.08 & 0.28 & 0.00 & 0.32 & 0.00 & 0.28 & 0.04 & 0.28 & 0.01 & 0.30 & 0.04 \\
\hline $20: 4 n-3$ & 0.58 & 0.00 & 0.58 & 0.01 & 0.54 & 0.02 & 0.55 & 0.05 & 0.55 & 0.03 & 0.57 & 0.05 \\
\hline $20: 5 n-3$ & 4.36 & 0.21 & 4.42 & 0.19 & 3.88 & 0.27 & $4 \cdot 15$ & 0.62 & $4 \cdot 22$ & 0.17 & $4 \cdot 26$ & 0.61 \\
\hline $22: 1 n-11$ & 1.42 & 0.16 & 1.53 & 0.24 & 1.21 & 0.12 & 1.52 & 0.40 & 1.45 & 0.15 & 1.41 & 0.36 \\
\hline $22: 1 n-9$ & 0.56 & 0.02 & 0.57 & 0.06 & 0.53 & 0.01 & 0.59 & 0.07 & 0.56 & 0.01 & 0.55 & 0.05 \\
\hline $22: 4 n-6$ & 0.10 & 0.01 & 0.10 & 0.01 & 0.10 & 0.01 & 0.11 & 0.01 & 0.10 & 0.00 & 0.11 & 0.01 \\
\hline $22: 5 n-6$ & 0.12 & 0.01 & 0.13 & 0.00 & 0.11 & 0.01 & 0.13 & 0.01 & 0.12 & 0.01 & 0.13 & 0.00 \\
\hline $22: 5 n-3$ & 2.07 & 0.15 & 2.10 & 0.20 & 1.88 & 0.15 & 2.08 & 0.27 & 1.99 & 0.10 & 2.09 & 0.26 \\
\hline $22: 6 n-3$ & 6.99 & 0.73 & $7 \cdot 41$ & 0.66 & 6.53 & 0.89 & 7.64 & 1.13 & 7.03 & 0.12 & $7 \cdot 27$ & 0.81 \\
\hline
\end{tabular}

${ }^{*}$ No significant differences were found for broodstock diet $(P>0.05)$, reminder diet $(P>0.05)$ and interaction of these two factors $(P>0.05)$ using the two-way ANOVA analysis.

accompanied by an enhanced utilisation of the low-FM/FO diet, as denoted by the better FCR, which could be related to the modulation of lipid and carbohydrate metabolism. There were no large differences in the proximate composition and fatty acid profiles of sea bream liver and muscle, reflecting the profound effect of the diet, regardless of the nutritional history of the different fish groups. Nevertheless, both broodstock diet and reminder diet had a significant effect on some major fatty acids in the liver such as 18:0, a terminal product of lipogenesis, and in the ratios 18:0:16:0 and, particularly, $18: 1: 16: 1$. Both $16: 0$ and $16: 1$ are substrates for elovl6, a key rate-limiting enzyme in the long-chain fatty acid elongation cycle and, therefore, the ratios
$18: 0: 16: 0$ and $18: 1: 16: 1$, are indicators of the activity of this enzyme. These results are in agreement with the hepatic elovl6 expression, which was down-regulated by the increase in LO in the broodstock diets and was correlated inversely to the 16:0 contents in the liver and directly to the $18: 0: 16: 0$ and $18: 1: 16: 1$, denoting a significant post-transcriptional effect. Besides, LO increase in broodstock diets also increased the hepatic 18:0:18:1 ratios in the 16-month-old offspring.

These results are in agreement with the 16:0 reduction and 18:0:18:1 increase in mice models with Elovl6 disruption, which showed protection against a high-SFA diet-induced insulin resistance that lead to hepatosteatosis similar to that of 

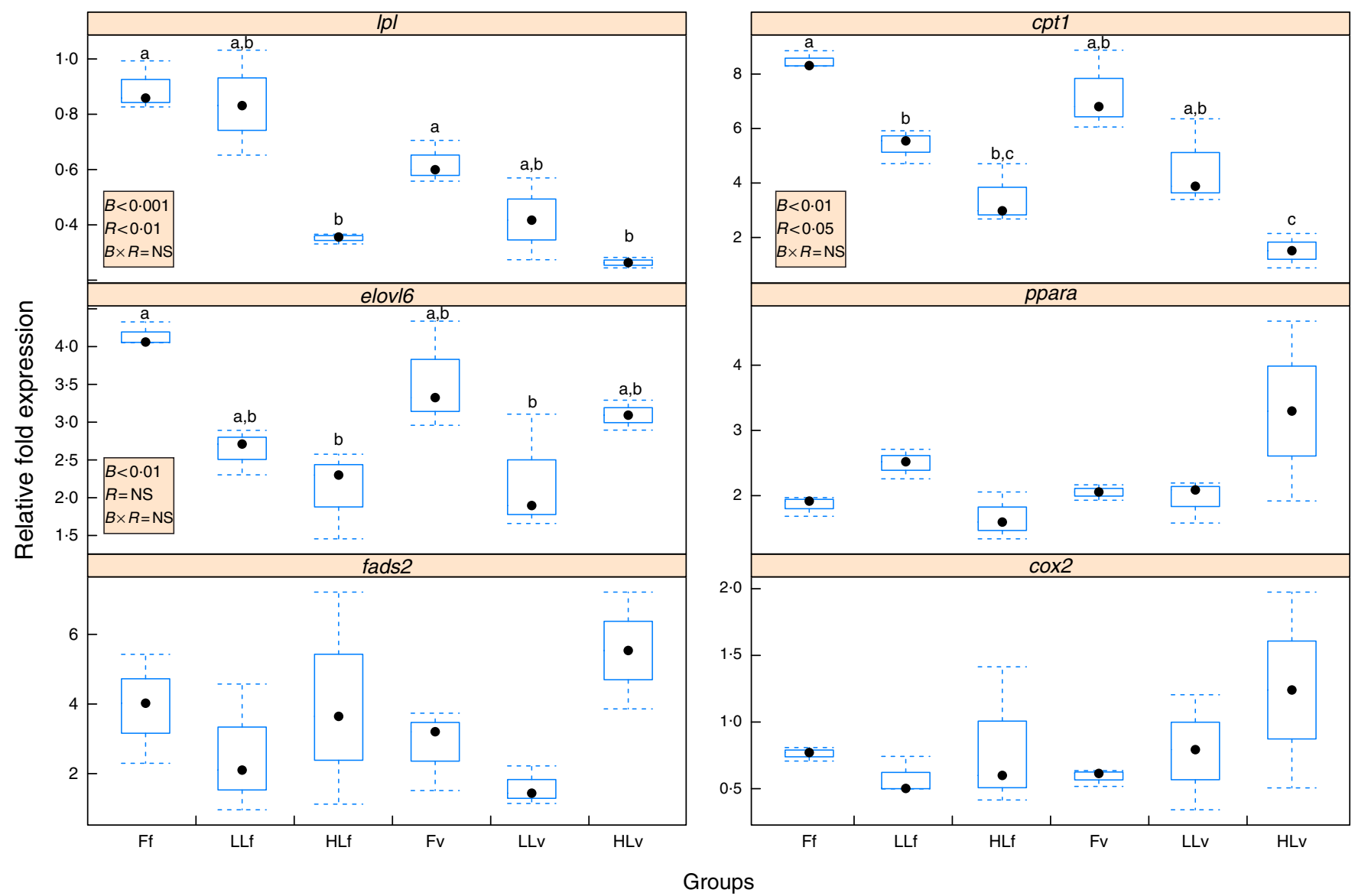

Fig. 2. Box and whisker plots of relative fold expression (groups $v$. control sample) of six different genes after challenging 16-month-old gilthead sea bream individuals with high-vegetable oil and high-meal feeds for 2 months. Ipl, lipoprotein lipase; elovl6, elongation of very long-chain fatty acids protein 6; fads2, fatty acid desaturase 2; cox2, cyclo-oxygenase-2; cpt1, carnitine palmitoyltransferase I; -....., maximum and minimum fold expression; $\square$, upper and lower quartiles; $\bullet$, median; $\lceil\rightarrow, P$ values of two-way ANOVA; $B$, broodstock diet; $R$, reminder diet; $B \times R$, interaction of these two parameters, $\mathrm{ns}, P>0.05 ; \mathrm{F}, 100 \%$ fish oil; $\mathrm{LL}, 40 \%$ fish oil $-60 \%$ linseed oil; and $\mathrm{HL}, 20 \%$ fish oil- $80 \%$ linseed oil; f, fish oil-based diet; $v$, reminder diet. $n 3$ for all the groups and genes. ${ }^{a, b, c}$ Mean values with unlike letters were significantly different between each group, no indications mean no significant difference $(P>0.05)$.

wild-type mice ${ }^{(51)}$. This protection was related to the restoration of hepatic insulin receptor substrate-2, suppression of hepatic protein kinase-C $\varepsilon$ and restoration of Akt phosphorylation ${ }^{(51)}$, overall, indicating a better utilisation of dietary carbohydrates under conditions of high-fat diet-induced insulin resistance. Indeed, insulin stimulates acetyl-CoA carboxylase that produces malonyl-CoA, which inhibits CPTI activity and affects utilisation of fatty acids and glucose as substrates ${ }^{(76)}$. Thus, genes related to fatty acid oxidation, such as $C P t I$, are down-regulated in mice with Elovl6 disruption ${ }^{(51)}$, whereas up-regulation of CPtI expression caused by intra-uterine growth restriction increases the risk of type 2 diabetes in adulthood ${ }^{(59)}$. In agreement, in the present study, down-regulation of elovl6 was correlated to down-regulation of cptI, a rate-limiting enzyme for fatty acid oxidation in mitochondria ${ }^{(77)}$. Moreover, increased $\mathrm{LO}$ in broodstock diet and increased plant-protein and lipid sources in the 4-month-old reminder diet induced the down-regulation of $c p t I$ in the gilthead sea bream offspring, evidencing a long-term nutritional programming effect. A down-regulation of cptIb gene expression was also found in the liver of juvenile rainbow trout by vitamin supplementation at first feeding showing that nutritional interventions during developmental plasticity (larval period) may provoke longer-term effects later in life ${ }^{(78)}$. CPtI expression in the liver of fish is down-regulated by the reduction of dietary PUFA, particularly, LC-PUFA ${ }^{(57,79)}$. Accordingly, cptII expression is also down-regulated in Atlantic salmon when dietary $\mathrm{FO}$ is substituted with $\mathrm{VO}^{(80,81)}$. In vitro studies in rainbow trout hepatocytes showed that ppara and cptI are up-regulated by MUFA and down-regulated by EPA, among other fatty acids ${ }^{(80,81)}$. In the present study $c p t 1 b$ expression was highly correlated to $18: 1 n-9$ and negatively correlated to $20: 5 n-3$ in the liver. Besides, LO increase in broodstock diets significantly reduced the liver contents of $16: 4 n-3$, an intermediate product of $\beta$-oxidation of EPA. In gilthead sea bream offspring, cptI expression in the liver is negatively correlated to ppara, suggesting that nutritional programing by LO reduces $\beta$-oxidation in the mitochondria but not in the peroxisomes. In mammals, parental feeding with a high-lipid diet lead to hypomethylation of four specific CpG dinucleotides in PPARa and the modification of the mRNA transcript in juvenile offspring $^{(60)}$. In gilthead sea bream fed a low-FM/FO diet, hepatic ppara is reportedly down-regulated, in association with retarded growth ${ }^{(82)}$. In the present study, ppara in the offspring of HLv fed a low-FM/FO diet was not down-regulated and 
growth was even increased instead of being reduced upon parental feeding with LO.

In previous studies, parental feeding of gilthead sea bream with increased substitution of $\mathrm{FO}$ with LO significantly up-regulated fads2 in 1-month-old offspring (S. Turkmen et al., unpublished results). Similarly, in Senegalese sole, parental nutritional history affects growth performance and the expression of $\Delta 4 \mathrm{fad}$ and elovl5 in the 2-month-old progeny ${ }^{(44)}$. However, in the present study, fads 2 of the 16-month-old fish did not show significant differences, which could be related to the strong influence of the very low-FM/FO diets fed to the 16-month-old sea bream. Indeed, fads 2 relative expression was high in all fish and up to 5.5 times higher than the values in gilthead sea bream juveniles fed commercial diets containing high levels of FM and FO (data not shown). This is in agreement with the up-regulation of fads 2 expression in fish fed reduced $n$-3 LC-PUFA diets rich in linolenic acid or LA ${ }^{(83)}$. Dietary changes did not affect fads 2 gene expression in Atlantic cod (Gadus morbua) either ${ }^{(84)}$, reportedly, related to the low dietary FO levels causing an up-regulation of this gene ${ }^{(49)}$ or to a post-transcriptional regulation ${ }^{(49)}$ as observed in other marine fish species ${ }^{(85)}$. Despite a slightly higher fads2 expression in offspring of broodstock fed LO and the reminder diet, individual differences among fish belonging to the same treatment lead to large variations with no significant differences among groups. Nevertheless, fads 2 expression in the liver was correlated with hepatic contents in $18: 4 n-3,18: 3 n-6,20: 5 n-3$, $22: 6 n-3$ and $22: 5 n-6$, intermediate and end products of desaturation activity by this enzyme ${ }^{(25)}$.

The down-regulation of $l p l$ expression in the liver of offspring from broodstock fed feeds with high LO levels, especially in those fish that received a low-FO/FM diet during juvenile stages, was correlated with reduced liver lipid contents, in agreement with the reduced lipid deposition associated with the down-regulation of $l p l$ expression in the liver of the gilthead sea bream in previous studies ${ }^{(86)}$. LPL is a determinant of lipid deposition or catabolism fate ${ }^{(58)}$. Thus, nutritional programing through regulation of different genes within the pathway of lipid metabolism including $l p l$, elovl 6 and $c p t I$ may prepare the offspring for a better utilisation of low-FM and low-FO diets, improving $\mathrm{VO}$ and $\mathrm{VM}$ utilisation and reducing the risk for hepatosteatosis described in gilthead sea bream fed these type of diets ${ }^{(87)}$. As occurs in mammals, nutritional signals through parental feeding may improve offspring fitness at later stages, triggering a 'predictive adaptive response ${ }^{(88)}$. Thus, in gilthead sea bream, offspring of broodstock fed moderate LO levels and fed the low-FM/FO diet during juvenile stages showed improved final body weight and feed utilisation.

To our knowledge, this is the first study that demonstrates the profound effects of $n-3$ LC-PUFA profiles in parental diets on long-term effects in fish offspring even later in life: that is, in those on the verge of their first sexual maturation. In mammals, $n-3$ LC-PUFA supplementation in maternal diets reduces premature births ${ }^{(89)}$ and enhances immune health ${ }^{(90,91)}$, growth, development and pancreatic tissue morphometry in the offspring $^{(92)}$. Besides, the nutritional programing effect of LC-PUFA on parental diet and the epigenetic regulation of gene expression has been also demonstrated in mammals ${ }^{(93)}$, implying different epigenetic and physiological mechanisms including cell differentiation, neuro-hormonal regulation, etc. ${ }^{94)}$, which have not yet been demonstrated in fish. The present study has also pointed out that nutritional programing through parental feeding interacts with the feeding history during juveniles stages, as feeding a low-FM/FO diet for only one month when fish were 4-months-old affected gene expression and fish performance later when fish were on the verge of reproduction, in agreement with studies in other vertebrates $^{(95)}$. In summary, partial replacement of FO with LO in parental diets during gilthead sea bream reproduction induced long-term persistent effects on transcription of selected genes in the offspring, which regulate energy metabolism in the liver for a better utilisation of diets high in $\mathrm{VO}$ and VM. Moreover, these long-term effects on gene transcription are further enhanced by feeding the offspring juveniles with diets high in VO and VM, which improved growth and feed utilisation. Studies are underway to better understand the potential epigenetic, metabolic and molecular mechanisms involved in the metabolic conditioning of offspring through parental nutrition in gilthead sea bream.

\section{Acknowledgements}

The authors wish to thank Dr Sadasivam Kaushik for his suggestions on the final version of the manuscript. Acknowledgement is also owed to an anonymous referee who gave very valuable suggestions.

This work has been (partly) funded under the EU seventh Framework Programme by the Advanced Research Initiatives for Nutrition \& Aquaculture (ARRAINA), project no. 288925.

S. T. conducted all experiments, analysed and evaluated all biological, biochemical and molecular analyses. Molecular biology samples were analysed by $\mathrm{S}$. T. with the supervision of M. J. Z. All trials were designed by S. T., D. M. and C. M. H.-C., and M. I. supervised the entire work. L. R. was involved in the formulation and the preparation of the diets. The paper was written by S. T. and M. I.

The authors declare that there are no conflicts of interest. The views expressed in this work are the sole responsibility of the authors and do not necessarily reflect the views of the European Commission.

\section{References}

1. Food and Agriculture Organization (2016) The State of World Fisheries and Aquaculture 2016. Contributing to Food Security and Nutrition for All, no. 78-92-5-108276-8. Roma: FAO.

2. Kaushik S \& Troell M (2010) Taking the fish-in fish-out ratio a step further. Aquacult Eur 35, 15-17.

3. Wang C, Harris WS, Chung M, et al. (2006) $n-3$ Fatty acids from fish or fish-oil supplements, but not $\alpha$-linolenic acid, benefit cardiovascular disease outcomes in primary- and secondaryprevention studies: a systematic review. Am J Clin Nutr 84, 5-17.

4. Benedito-Palos L, Saera-Vila A, Calduch-Giner J-A, et al. (2007) Combined replacement of fish meal and oil in practical diets for fast growing juveniles of gilthead sea bream (Sparus aurata L.): networking of systemic and local components of GH/IGF axis. Aquaculture 267, 199-212. 
5. Kaushik S, Coves D, Dutto G, et al. (2004) Almost total replacement of fish meal by plant protein sources in the diet of a marine teleost, the European seabass, Dicentrarchus labrax. Aquaculture 230, 391-404.

6. Le Boucher R, Vandeputte M, Dupont-Nivet M, et al. (2013) Genotype by diet interactions in European sea bass (Dicentrarchus labrax L. 1756): nutritional challenge with totally plant-based diets. J Anim Sci 91, 44-56.

7. Le Boucher R, Vandeputte M, Dupont-Nivet M, et al. (2011) A first insight into genotype $\times$ diet interactions in European sea bass (Dicentrarchus labrax L. 1756) in the context of plant-based diet use. Aquacult Res 42, 583-592.

8. Shepherd J \& Bachis E (2014) Changing supply and demand for fish oil. Aquacult Econ Manage 18, 395-416.

9. Montero D \& Izquierdo M (2010) Welfare and health of fish fed vegetable oils as alternative lipid sources to fish oil. In Fish Oil Replacement and Alternative Lipid Sources in Aquaculture Feeds, pp. 439-485 [GM Turchini, WK Ng and DR Tocher, editors]. Boca Raton, FL: CRC Press.

10. Eroldoğan TO, Yılmaz AH, Turchini GM, et al. (2013) Fatty acid metabolism in European sea bass (Dicentrarchus labrax): effects of $n-6$ PUFA and MUFA in fish oil replaced diets. Fish Physiol Biochem 39, 941-955.

11. Rosenlund G, Corraze G, Izquierdo M, et al. (2010) The effects of fish oil replacement on nutritional and organoleptic qualities of farmed fish. In Fish Oil Replacement and Alternative Lipid Sources in Aquaculture Feeds, pp. 487-522 [GM Turchini, WK $\mathrm{Ng}$ and DR Tocher, editors]. Boca Raton, FL: CRC Press.

12. Izquierdo MS, Montero D, Robaina L, et al. (2005) Alterations in fillet fatty acid profile and flesh quality in gilthead seabream (Sparus aurata) fed vegetable oils for a long term period. Recovery of fatty acid profiles by fish oil feeding. Aquaculture 250, 431-444.

13. Yilmaz HA, Corraze G, Panserat S, et al. (2016) Effects of alternate feeding with different lipid sources on fatty acid composition and bioconversion in European sea bass (Dicentrarchus labrax). Aquaculture 464, 28-36.

14. Betancor MB, Sprague M, Usher S, et al. (2015) A nutritionallyenhanced oil from transgenic Camelina sativa effectively replaces fish oil as a source of eicosapentaenoic acid for fish. Sci Rep 5, 8104.

15. Sargent J, Tocher D \& Bell J (2002) The lipids. In Fish Nutrition, pp. 181-257 [JE Halver and RW Hardy, editors]. San Diego, CA: Academic Press.

16. Castro LF, Tocher DR \& Monroig O (2016) Long-chain polyunsaturated fatty acid biosynthesis in chordates: insights into the evolution of Fads and Elovl gene repertoire. Prog Lipid Res 62, 25-40.

17. Leaver MJ, Villeneuve LA, Obach A, et al. (2008) Functional genomics reveals increases in cholesterol biosynthetic genes and highly unsaturated fatty acid biosynthesis after dietary substitution of fish oil with vegetable oils in Atlantic salmon (Salmo salar). BMC Genomics 9, 299.

18. Sargent J, Bell G, McEvoy L, et al. (1999) Recent developments in the essential fatty acid nutrition of fish. Aquaculture 177, 191-199.

19. Tocher DR (2010) Fatty acid requirements in ontogeny of marine and freshwater fish. Aquacult Res 41, 717-732.

20. Monroig Ó, Tocher DR \& Navarro JC (2013) Biosynthesis of polyunsaturated fatty acids in marine invertebrates: recent advances in molecular mechanisms. Mar Drugs 11, 3998-4018.

21. Monroig Ó, Wang S, Zhang L, et al. (2012) Elongation of longchain fatty acids in rabbitfish Siganus canaliculatus: cloning, functional characterisation and tissue distribution of Elovl5and Elovl4-like elongases. Aquaculture 350-353, 63-70.
22. Navarro-Guillén C, Engrola S, Castanheira F, et al. (2014) Effect of varying dietary levels of LC-PUFA and vegetable oil sources on performance and fatty acids of Senegalese sole post larvae: puzzling results suggest complete biosynthesis pathway from C18 PUFA to DHA. Comp Biochem Physiol B Biochem Mol Biol 167, 51-58.

23. Xu H, Dong X, Ai Q, et al. (2014) Regulation of tissue LC-PUFA contents, $\Delta 6$ fatty acyl desaturase (FADS2) gene expression and the methylation of the putative FADS2 gene promoter by different dietary fatty acid profiles in Japanese seabass (Lateolabrax japonicus). PLOS ONE 9, e87726.

24. Sargent JR, Bell JG, Bell MV, et al. (1995) Requirement criteria for essential fatty acids. J Appl Ichthyol 11, 183-198.

25. Tocher DR (2003) Metabolism and functions of lipids and fatty acids in teleost fish. Rev Fish Sci 11, 107-184.

26. Burton T \& Metcalfe NB (2014) Can environmental conditions experienced in early life influence future generations? Proc Biol Sci 281, 20140311.

27. Burdge GC, Hanson MA, Slater-Jefferies JL, et al. (2007) Epigenetic regulation of transcription: a mechanism for inducing variations in phenotype (fetal programming) by differences in nutrition during early life? Br J Nutr 97, 1036-1046.

28. Curley JP, Mashoodh R \& Champagne FA (2011) Epigenetics and the origins of paternal effects. Horm Behav 59, 306-314.

29. Gluckman PD \& Hanson MA (2004) Living with the past: evolution, development, and patterns of disease. Science $\mathbf{3 0 5}$, $1733-1736$.

30. Langley-Evans SC (2015) Nutrition in early life and the programming of adult disease: a review. J Hum Nutr Diet 28, Suppl. 1, 1-14.

31. Gotoh T (2015) Potential of the application of epigenetics in animal production. Anim Prod Sci 55, 145-158.

32. Öst A \& Pospisilik JA (2015) Epigenetic modulation of metabolic decisions. Curr Opin Cell Biol 33, 88-94.

33. Lillycrop KA, Phillips ES, Jackson AA, et al. (2005) Dietary protein restriction of pregnant rats induces and folic acid supplementation prevents epigenetic modification of hepatic gene expression in the offspring. J Nutr 135, 1382-1386.

34. Morgan HD, Sutherland HG, Martin DI, et al. (1999) Epigenetic inheritance at the agouti locus in the mouse. Nat Genet 23, 314-318.

35. Mossa F, Walsh SW, Ireland JJ, et al. (2015) Early nutritional programming and progeny performance: Is reproductive success already set at birth? Animal Frontiers 5, 18-24.

36. Clarkson M, Migaud H, Metochis C, et al. (2017) Early nutritional intervention can improve utilisation of vegetable-based diets in diploid and triploid Atlantic salmon (Salmo salar L.). Br J Nutr 118, 17-29.

37. Geurden I, Borchert P, Balasubramanian MN, et al. (2013) The positive impact of the early-feeding of a plant-based diet on its future acceptance and utilisation in rainbow trout. PLOS ONE 8, e83162.

38. Mellery J, Brel J, Dort J, et al. (2017) A n-3 PUFA depletion applied to rainbow trout fry (Oncorbynchus mykiss) does not modulate its subsequent lipid bioconversion capacity. BrJ Nutr 117, 187-199.

39. Rocha F, Dias J, Engrola S, et al. (2014) Glucose overload in yolk has little effect on the long-term modulation of carbohydrate metabolic genes in zebrafish (Danio rerio). J Exp Biol 217, 1139-1149.

40. Turkmen S, Castro PL, Caballero MJ, et al. (2017) Nutritional stimuli of gilthead seabream (Sparus aurata) larvae by dietary fatty acids: effects on larval performance, gene expression and neurogenesis. Aquacult Res 48, 202-213.

41. Vagner M, Zambonino Infante JL, Robin JH, et al. (2007) Is it possible to influence European sea bass (Dicentrarchus 
labrax) juvenile metabolism by a nutritional conditioning during larval stage? Aquaculture 267, 165-174.

42. Vagner M, Robin JH, Zambonino Infante JL, et al. (2007) Combined effects of dietary HUFA level and temperature on sea bass (Dicentrarchus labrax) larvae development. Aquaculture 266, 179-190.

43. Vagner M, Robin JH, Zambonino-Infante JL, et al. (2009) Ontogenic effects of early feeding of sea bass (Dicentrarchus labrax) larvae with a range of dietary $n-3$ highly unsaturated fatty acid levels on the functioning of polyunsaturated fatty acid desaturation pathways. BrJ Nutr 101, 1452-1462.

44. Morais S, Mendes AC, Castanheira MF, et al. (2014) New formulated diets for Solea senegalensis broodstock: effects of parental nutrition on biosynthesis of long-chain polyunsaturated fatty acids and performance of early larval stages and juvenile fish. Aquaculture 432, 374-382.

45. Izquierdo MS, Turkmen S, Montero D, et al. (2015) Nutritional programming through broodstock diets to improve utilization of very low fishmeal and fish oil diets in gilthead sea bream. Aquaculture 449, 18-26.

46. Otero-Ferrer F, Izquierdo M, Fazeli A, et al. (2016) Embryonic developmental plasticity in the long-snouted seahorse (Hippocampus reidi, Ginsburg 1933) in relation to parental preconception diet. Reprod Fertil Dev 28, 1020-1028.

47. Fernández-Palacios H, Norberg B, Izquierdo M, et al. (2011) Effects of broodstock diet on eggs and larvae. In Larval Fish Nutrition, pp. 151-181 [JG Holt, editor]. Oxford: Wiley-Blackwell.

48. Izquierdo MS, Fernandez-Palacios H \& Tacon AGJ (2001) Effect of broodstock nutrition on reproductive performance of fish. Aquaculture 197, 25-42.

49. Izquierdo MS, Robaina L, Juárez-Carrillo E, et al. (2008) Regulation of growth, fatty acid composition and delta 6 desaturase expression by dietary lipids in gilthead seabream larvae (Sparus aurata). Fish Physiol Biochem 34, 117-127.

50. Monroig Ó, Navarro JC \& Tocher DR (2011) Long-chain polyunsaturated fatty acids in fish: recent advances on desaturases and elongases involved in their biosyntesis. Avances en Nutrición Acuícola 11, 257-283.

51. Matsuzaka T \& Shimano H (2009) Elovl6: a new player in fatty acid metabolism and insulin sensitivity. J Mol Med 87, 379-384.

52. Clarke SD (2001) Polyunsaturated fatty acid regulation of gene transcription: a molecular mechanism to improve the metabolic syndrome. J Nutr 131, 1129-1132.

53. Bell G \& Koppe W (2010) Lipids in aquafeeds. In Fish Oil Replacement and Alternative Lipid Sources in Aquaculture Feeds, pp. 21-60 [GM Turchini, WK Ng and D Tocher, editors]. Boca Raton, FL: CRC Press.

54. Raclot T, Groscolas R, Langin D, et al. (1997) Site-specific regulation of gene expression by $n-3$ polyunsaturated fatty acids in rat white adipose tissues. J Lipid Res 38, 1963-1972.

55. Kjaer MA, Todorcevic M, Torstensen BE, et al. (2008) Dietary n-3 HUFA affects mitochondrial fatty acid beta-oxidation capacity and susceptibility to oxidative stress in Atlantic salmon. Lipids 43, 813-827.

56. Vestergren AS, Trattner S, Pan J, et al. (2012) The effect of combining linseed oil and sesamin on the fatty acid composition in white muscle and on expression of lipidrelated genes in white muscle and liver of rainbow trout (Oncorbynchus mykiss). Aquacult Int 21, 843-859.

57. Xue X, Hixson SM, Hori TS, et al. (2015) Atlantic salmon (Salmo salar) liver transcriptome response to diets containing Camelina sativa products. Comp Biochem Physiol Part D Genomics Proteomics 14, 1-15.

58. Leaver MJ, Bautista JM, Bjornsson BT, et al. (2008) Towards fish lipid nutrigenomics: Current state and prospects for fin-fish aquaculture. Rev Fish Sci 16, 73-94.
59. Corbin KD (2011) Metabolic syndrome, obesity, and diabetes. In Nutrition in Epigenetics, pp. 145-164 [MD Niculescu and P Haggarty, editors]. Oxford: Wiley-Blackwell.

60. Lillycrop KA, Phillips ES, Torrens C, et al. (2008) Feeding pregnant rats a protein-restricted diet persistently alters the methylation of specific cytosines in the hepatic PPAR $\alpha$ promoter of the offspring. BrJ Nutr 100, 278-282.

61. Ishikawa TO \& Herschman HR (2007) Two inducible, functional cyclooxygenase- 2 genes are present in the rainbow trout genome. J Cell Biochem 102, 1486-1492.

62. Torrecillas S, Robaina L, Caballero MJ, et al. (2017) Combined replacement of fishmeal and fish oil in European sea bass (Dicentrarchus labrax): production performance, tissue composition and liver morphology. Aquaculture 474, 101-112.

63. Association of Official Analytical Chemists (1995) Official Methods of Analysis of AOAC International, 15th ed. Arlington, VA: AOAC International

64. Folch J, Lees M \& Sloane-Stanley G (1957) A simple method for the isolation and purification of total lipids from animal tissues. J Biol Chem 226, 497-509.

65. Christie WW (1982) Lipid Analysis. Oxford: Pergamon Press.

66. Izquierdo MS, Watanabe T, Takeuchi T, et al. (1990) Optimum EFA levels in Artemia to meet the EFA requirements of red sea bream (Pagrus major). In The Current Status of Fish Nutrition in Aquaculture: The Proceedings of the Third International Symposium on Feeding and Nutrition in Fish. Toba, pp. 221-232.

67. Xie F, Xiao P, Chen D, et al. (2012) miRDeepFinder: a miRNA analysis tool for deep sequencing of plant small RNAs. Plant Mol Biol 80, 75-84.

68. Benedito-Palos L, Ballester-Lozano G \& Pérez-Sánchez J (2014) Wide-gene expression analysis of lipid-relevant genes in nutritionally challenged gilthead sea bream (Sparus aurata). Gene 547, 34-42.

69. Sepulcre MP, López-Castejón G, Meseguer J, et al. (2007) The activation of gilthead seabream professional phagocytes by different PAMPs underlines the behavioural diversity of the main innate immune cells of bony fish. Mol Immunol 44, 2009-2016.

70. Boukouvala E, Leaver MJ, Favre-Krey L, et al. (2010) Molecular characterization of a gilthead sea bream (Sparus aurata) muscle tissue cDNA for carnitine palmitoyltransferase 1B (CPT1B). Comp Biochem Physiol B Biochem Mol Biol 157, 189-197.

71. Livak KJ \& Schmittgen TD (2001) Analysis of relative gene expression data using real-time quantitative PCR and the 2 (-Delta Delta C(T)) Method. Methods 25, 402-408.

72. Schmittgen TD \& Livak KJ (2008) Analyzing real-time PCR data by the comparative CT method. Nat Protoc 3, 1101-1108.

73. Sarkar D (2008) Lattice: Multivariate Data Visualization with $R$. New York, NY: Springer Science \& Business Media.

74. Mathers J (2007) Early nutrition: impact on epigenetics. Forum Nutr 60, 42-48.

75. Monaghan P (2008) Early growth conditions, phenotypic development and environmental change. Philos Trans $R$ Soc Lond B Biol Sci 363, 1635-1645.

76. Zammit VA (1999) The malonyl-CoA-long-chain acyl-CoA axis in the maintenance of mammalian cell function. Biochem $J$ 343, 505-515.

77. Kolditz C, Borthaire M, Richard N, et al. (2008) Liver and muscle metabolic changes induced by dietary energy content and genetic selection in rainbow trout (Oncorbynchus mykiss). Am J Physiol Regul Integr Comp Physiol 294, R1154-R1164.

78. Panserat S, Marandel L, Geurden I, et al. (2017) Muscle catabolic capacities and global hepatic epigenome are modified in juvenile rainbow trout fed different vitamin levels at first feeding. Aquaculture 468, 515-523. 
79. Morash AJ, Bureau DP \& McClelland GB (2009) Effects of dietary fatty acid composition on the regulation of carnitine palmitoyltransferase (CPT) I in rainbow trout (Oncorbynchus mykiss). Comp Biochem Physiol B Biochem Mol Biol 152, 85-93.

80. Jordal AE, Torstensen BE, Tsoi S, et al. (2005) Dietary rapeseed oil affects the expression of genes involved in hepatic lipid metabolism in Atlantic salmon (Salmo salar L.). J Nutr 135, 2355-2361.

81. Torstensen B, Ng W \& Tocher D (2010) The effects of fish oil replacement on lipid metabolism of fish. In Fish Oil Replacement and Alternative Lipid Sources in Aquaculture Feeds, pp. 405-437 [GM Turchini, WK Ng and DR Tocher, editors]. Boca Raton, FL: CRC Press.

82. Benedito-Palos L, Ballester-Lozano GF, Simó P, et al. (2016) Lasting effects of butyrate and low FM/FO diets on growth performance, blood haematology/biochemistry and molecular growth-related markers in gilthead sea bream (Sparus aurata). Aquaculture 454, 8-18.

83. Vagner M \& Santigosa E (2011) Characterization and modulation of gene expression and enzymatic activity of delta- 6 desaturase in teleosts: a review. Aquaculture 315, 131-143.

84. Tocher DR, Zheng X, Schlechtriem C, et al. (2006) Highly unsaturated fatty acid synthesis in marine fish: cloning, functional characterization, and nutritional regulation of fatty acyl $\Delta 6$ desaturase of Atlantic cod (Gadus morhua L.). Lipids 41, 1003-1016.

85. Geay F, Santigosa ICE, Corporeau C, et al. (2010) Regulation of FADS2 expression and activity in European sea bass (Dicentrarchus labrax, L.) fed a vegetable diet. Comp Biochem Physiol B: Biochem Mol Biol 156, 237-243.

86. Saera-Vila A, Calduch-Giner JA, Gómez-Requeni $\mathrm{P}$, et al. (2005) Molecular characterization of gilthead sea bream (Sparus aurata) lipoprotein lipase. Transcriptional regulation by season and nutritional condition in skeletal muscle and fat storage tissues. Comp Biochem Physiol B Biochem Mol Biol 142, 224-232.

87. Montero D, Tort L, Izquierdo M, et al. (1996) Effect of $\alpha$-tocopherol and n-3 HUFA deficient diets on blood cells, selected immune parameters and proximate body composition of gilthead seabream (Sparus aurata). In Modulators of Immune Response The Evolutionary Trail vol. 9, pp. 251-266 [JS Stolen, TC Fletcher, CJ Secombes, et al., editors]. Fair Haven, CT: SOS Publications.

88. Gluckman PD, Hanson MA \& Spencer HG (2005) Predictive adaptive responses and human evolution. Trends Ecol Evol 20, $527-533$.

89. Cetin I \& Koletzko B (2008) Long-chain $\omega$-3 fatty acid supply in pregnancy and lactation. Curr Opin Clin Nutr Metab Care 11, 297-302.

90. Calder P, Dangour A, Diekman C, et al. (2010) Essential fats for future health. Proceedings of the 9th Unilever Nutrition Symposium, 26-27 May 2010. Eur J Clin Nutr 64, S1-S13.

91. Uauy R, Corvalan C \& Dangour AD (2009) Rank Prize Lecture Global nutrition challenges for optimal health and well-being. Proc Nutr Soc 68, 34-42.

92. Siemelink M, Verhoef A, Dormans JA, et al. (2002) Dietary fatty acid composition during pregnancy and lactation in the rat programs growth and glucose metabolism in the offspring. Diabetologia 45, 1397-1403.

93. Jaenisch R \& Bird A (2003) Epigenetic regulation of gene expression: how the genome integrates intrinsic and environmental signals. Nat Genet 33, 245-254.

94. Hyatt MA, Gopalakrishnan GS, Bispham J, et al. (2007) Maternal nutrient restriction in early pregnancy programs hepatic mRNA expression of growth-related genes and liver size in adult male sheep. $J$ Endocrinol 192, 87-97.

95. Duque-Guimaraes DE \& Ozanne SE (2013) Nutritional programming of insulin resistance: causes and consequences. Trends Endocrinol Metab 24, 525-535. 